\title{
Information Acquisition, Ideology and Turnout: Theory and Evidence from Britain
}

\author{
Valentino Larcinese* \\ Department of Government and STICERD \\ London School of Economics and Political Science
}

PEPP/18

March 2006

\author{
Political Economy and Public Policy Series \\ The Suntory Centre \\ Suntory and Toyota International Centres for \\ Economics and Related Disciplines \\ London School of Economics and Political Science \\ Houghton Street \\ London WC2A $2 \mathrm{AE}$
}

Tel: (020) 79556674

\footnotetext{
* I wish to thank Oriana Bandiera, Richard Blundell, Harold Clarke, Guillaume Frechette, Cesar Martinelli, Maria Pia Monteduro, Ian Preston, Imran Rasul, David Strömberg, Leo Rizzo and Donald Wittman as well as participants in a number of meetings and seminars for their useful comments and suggestions; I am especially grateful to Tim Besley for very helpful discussions during all stages of this project and for comments and suggestions on this as well as preliminary versions of this paper. I remain the sole responsible for limits and errors of this work. Financial support from the European Commission under the TMR Scheme (Marie Curie Fellowship) and from ESRC is gratefully acknowledged. I will be a visiting scholar at the Massachusetts Institute of Technology during the 2005-06 academic year. Address for correspondence: Department of Political Science, MIT, 77 Massachusetts avenue, Cambridge MA 021394307, USA. Tel. +1 617253 6619. E-mail: larcines@mit.edu. Personal webpage: http://personal.lse.ac.uk/LARCINES/
} 


\begin{abstract}
The amount of political information that voters decide to acquire during an electoral campaign depends, among other things, on prior ideological beliefs about parties and/or candidates. Voters that are ex ante indifferent about the candidates attach little value to information because they perceive that voting itself will have little value. Voters that are ex ante very ideological also attach little value to information because they think that the news will hardly change their opinion. Thus, high incentives to be informed can be found at intermediate levels of ideological strength. Moreover, the impact of increased political knowledge on turnout is asymmetric: New information increase the probability of voting of indifferent voters but decrease that of very ideological voters. These results are derived within a decision theoretical model of information acquisition and turnout that combines the Riker-Ordeshook (1968) approach to voting behaviour with the Becker (1965) approach to "personal production functions". These predictions are then tested on survey data from the 1997 British Election Study. Our empirical findings are compatible with all the results of the theoretical exercise.
\end{abstract}

JEL Nos.: D72, D83.

Keywords: elections, turnout, political knowledge, information, ideology, partisanship, political participation, mass media.

(C) The author. All rights reserved. Short sections of text, not to exceed two paragraphs, may be quoted without explicit permission provided that full credit, including $\odot$ notice, is given to the source 


\section{Introduction}

Individual predispositions like party identification and ideology are pervasive predictors of voting behavior. In their celebrated book The American Voter, Campbell et al. (1960, p.121) claim that "few facts are of greater importance for our national elections than the lasting attachment of tens of millions of Americans to one of the parties". This basic finding has been more recently re-iterated by Miller \& Shanks (1996). Erikson, Wright \& McIver (1993) have provided extensive evidence from exit polls data of the importance of both partisanship and ideology in voters' presidential choices during the 1984 and 1988 elections. Rosenstone and Hansen (1993) have shown that changes in partisanship determine corresponding variations in turnout while Bartels (2000) and Hetherington (2001) have provided evidence of resurging partisanship in the electorate, after a declining period that reached its minimum during the seventies. Other national studies reach very similar conclusions. In the UK, which will constitute the object of our empirical study, partisanship and ideology probably play an even greater role, both having historically strong links with social class and other economic and social variables (Bartle, 1998; Denver, 2004). Empirical research on Britain consistently finds that voters with strong predispositions tend to vote on the basis of their "general values and their overall perception of what the parties stand for"1 ${ }^{1}$.

While partisanship and ideology tend to be correlated with interest in politics and turnout, they are also often associated with unconditional voting decisions. This makes it easier for politicians to abuse the trust they receive, making them less accountable and less responsive to the public interest ${ }^{2}$. On a normative ground, therefore, partizan and ideological voters can be contrasted with independent citizens, who make informed and dependable decisions on policy issues (Feddersen and Pesendorfer, 1996 and 1999). A growing body of theoretical and empirical research has recently stressed the positive

\footnotetext{
${ }^{1}$ Heath, Jowell and Curtis (1985), p.107.

${ }^{2}$ Some scholars, however, argue that a long term relationship between a party and specific constituents can help voters with little or ordinary political knowledge to take decisions that reflect their interests (Popkins,1991; Wittman, 1995; Lupia and McCubbins,1998) .
} 
role of voter information on the quality of public decisions (Besley and Burgess, 2002; Besley and Prat, 2005). Better informed voters are both more responsive to platform announcements and more likely to vote (Palfrey and Poole, 1987). Political knowledge is also a very good predictor of electoral turnout, even controlling for a number of individual characteristics $^{3}$ (Delli Carpini and Keeter, 1996). Recent evidence also shows that the correlation between voter political knowledge and turnout contains a strong causality component (Larcinese, 2005; Lassen, 2005).

In spite of the growing interest in the role of information in elections and the well established evidence on the impact of ideology and partisanship, relatively little attention has been devoted to the important interactions that occur between political predispositions and political knowledge. Among the few exceptions, Achen (1992) proposes a model of voter rational learning in the presence of exogenous information, assuming that partisan attitudes are formed within a Bayesian updating process: new information receives less weight when many pieces of information have already been received. This can explain the stability of partisan attitudes after a certain age. ${ }^{4}$ On the empirical side, Palfrey and Poole (1987) use ICPSR survey data from the 1980 US presidential election to show that information is significantly related to both political extremism and turnout. Voter information is positively correlated with ideological extremism and negatively correlated with indifference between candidates. Moreover, not only are more informed citizens more likely to vote, but their vote is also more predictable, in the sense that they exhibit less randomness when voting behaviour is predicted using political preferences ${ }^{5}$.

In this paper I study the link between political predispositions and incentives to acquire information and reconsider the relationship between prior beliefs, information and turnout

\footnotetext{
${ }^{3}$ Sanders (2001) studies the 1996 US presidential election and shows the importance for turnout of perceived uncertainty about candidates.

${ }^{4}$ Gerber and Green (1996), however, show that stable party identification is not necessarily the consequence of rational learning when party platforms are not stable over time.

${ }^{5}$ Preferences are recovered either by respondents' self-placement on a liberal-conservative scale, relative to their placement of candidates, or from self-placement on a number of issues like defense spending, inflation or government aid to minority groups.
} 
under this new light ${ }^{6}$. I will generally refer to political predispositions by using the word ideology. This is admittedly a minimalistic interpretation of this term, that is often used to indicate broad theoretical constructions and general values that can often go beyond the realm of politics. Our purpose is comparatively limited but the simplification proposed captures an important aspect of ideology in politics: during elections, these complex set of principles are translated into beliefs about candidates. This simplification allows us to formalize an important point: That people with different prior beliefs about parties and candidates have also differentiated incentives to acquire information. In general, the instrumental value of political information depends on the possibility (ex ante) that new information may induce a change in behaviour and this, in turn, depends on existing beliefs ${ }^{7}$.

The starting point of our analysis is a formal model that tries to capture the determinants of citizens' political knowledge by combining the Riker and Ordeshook (1968) model of the calculus of voting with the Becker (1965) approach to the modeling of individual production functions. Approaching voting behaviour by using the methodology of rational choice theory, as I do in this paper, means that an attempt should be made to also explain political information acquisition using the same tools. ${ }^{8}$ I present therefore a decision-theoretical model where the demand for political information is the outcome of a rational process, with its costs and benefits. Information acquisition is modeled as an individual production process, where inputs are mass media and time devoted to their

\footnotetext{
${ }^{6}$ On a purely empirical ground, the fact that ideological factors influence information acquisition is not a new theme in empirical social science: voters tend to select their information sources on the basis of ideologies and partizanship and, for this reason, mass media have been often found to reinforce people' beliefs rather than persuade them (Lazarsfeld, Berelson and Gaudet (1944), Berelson, Lazarsfeld and McPhee, 1954).

${ }^{7}$ Using the term ideology makes also clearer that, when I refer to partisanship, I am only using a very narrow definition of the term, namely the belief that, prospectively, one party can satisfy one's preferences better than others. In the literature, the word partisanship has often a broader meaning that encompasses social identity, social class (especially in Britain) and sense of belonging to a given group. Although these elements can be very important for voting decision-making, they are not the focus of this paper.

${ }^{8}$ Matsusaka (1995) is, to my knowledge, the only work that considers the link between information and turnout with endogenous information acquisition. This is done in the context of a decision-theoretical model: increasing the "confidence" on the link between candidate choice and final outcome, information increases the probability of each voter to turn out in the election.
} 
usage. Citizens are endowed with different capabilities to acquire and process news and are therefore able to grasp more or less information from the same exposure to media: In this sense, a number of observable individual and systemic characteristics act as internal and external constraints to the capability to be informed and represent therefore good predictors of political knowledge. In this way, the model rationalizes several positive correlations found in empirical research, like that between education and turnout (Wolfinger and Rosenstone, 1980; Matsusaka and Palda, 1999; Milligan et al., 2004).

Political dispositions are represented by prior beliefs about the quality of candidates. In general, most people have their own prior opinions on political matters: these are reflected on both policy preferences and beliefs about how to reach given aims. These priors can be shaped by the influence of other people (e.g. parents), by a sense of belonging to a certain group, by personal experiences and so on. It is out of question that such prior beliefs, however formed, play an important role in voting decisions and on turnout itself. Moreover, and more interestingly from our perspective, they can have an influence on the decision to be informed. The amount of political information that voters decide to acquire during an electoral campaign depends, among other things, on prior ideological beliefs about parties and/or candidates and it will be shown to be, other things equal, nonmonotonic in ideological strenght. Voters that are ex ante indifferent about the candidates attach little value to information because they perceive that voting itself will have little value. Voters that are ex ante very ideological also attach little value to information because they think that the news will hardly change their opinion. Thus, high incentives to be informed can be found at intermediate levels of ideological strenght. This theoretical result is confirmed by an empirical analysis of data from the British Election Study (BES), especially when left-right self-placement is used as a measure of ideology.

The impact of ideology and information on voter turnout is then reconsidered within this extended framework. Ideology can now influence voting both directly (as a prior belief) and indirectly, via its impact on political knowledge. Nevertheless, the net effect 
of ideology on turnout remains always positive. This is not the case for information, which has a positive impact on the voting probability of non-partizan voters but a negative effect on that of the partizans. Therefore, empirical estimations of turnout that want to gauge the relative impact of ideology and political knowledge should include an interaction term to unveil the significant heterogeneity of the impact of information. This result is also tested by using BES data: All empirical findings are again compatible with the results of the theoretical exercise.

The paper is organized as follows. The next section introduces the main features of the theoretical model while section 3 analyses the case of a non-polarized polity, when each voter has prior beliefs that make her substantially indifferent (ex ante) about the candidates. In section 4 I turn to the role of ideology, considering prior beliefs that attach different values to the candidates. Section 5 provides some empirical evidence from the British Election Study and and Section 6 concludes. Further details about both the model and the data can be found in the Appendices.

\section{The model}

Consider a polity with two political parties $I$ (incumbent) and $O$ (opponent) and a set $\Omega$ of citizens who vote to elect a public decision-maker. The incumbent politician decides the value of a public policy parameter $a \in[0, \bar{a}]$. We assume a one-to-one relationship between politicians and policies: in other terms (abusing the notation) candidate $a$ delivers policy $a$. The incumbent policy-maker $a_{I}$ faces an opponent selected by party $O$. The opponent candidate selection process is represented by a probability distribution function $F_{O}(a)$,with corresponding density function $f_{O}(a)$. On the other side, when the politician in office implements her preferred policy $a_{I}$ she reveals her type to citizens: therefore, while $a_{I}$ is common knowledge, citizens do not know the opponent's type $a_{O}$ but only her distribution $F_{O}(a)$.

Citizens' preferences over policies are represented by a utility function $V(a)$. I assume 
that all citizens have the same preferences over $a$ and that $V^{\prime}(a)>0$. In other terms, $a$ is considered as a valence issue, or a generally accepted measure of good governance. This allows us to focus explicitly on beliefs rather than preferences. The validity of such simplification rests, in the end, on the way the policy space is defined. In modeling voting, virtually any policy issue can be represented as a valence issue with heterogeneous beliefs: the most appropriate modeling choice depends then on the purpose of the model. This is to say that citizens, rather than differing on their final aims, can be represented as having different opinions on the most appropriate ways to reach their aims, if we redefine what we intend by aim. Let us take the example of health care: not many politicians would claim they don't care about public health. However, different strategies to reach good health services are rationalizable and are indeed rationalized during electoral campaigns. Another good example is gun control: both the supporters and the opposers of increasing gun regulation claim that their advocate policy is better for public order and in order to increase the average citizen's safety. Both cases are logically possible and evidence is often not clear or easily manipulable: When the citizens' utility function is defined in terms of meta-preferences over final private ends rather than over policies, then heterogeneity becomes more relevant for beliefs than for actual preferences. Heterogeneous preferences on policies can in this case be introduced at the cost of extra technical complications and little new insights.

I assume then that citizens have different prior beliefs about the distribution $F_{O}(a)$. The set of admittable prior distribution functions is indicated with $\mathcal{F}$. During the electoral campaign, citizens can gather information on the opponent candidate ${ }^{9}$. They are endowed with an information gathering technology that is represented by the probability $q(t, k \mid E, M)$ to learn the realization $a_{O}$. The inputs of this personal information production function are an information source of quality $k \in \mathcal{K} \subset \mathbb{R}_{+}$, and time $t \in \mathcal{T} \subset \mathbb{R}_{+}$ devoted to extract information from this source ${ }^{10}$. The opportunity cost of time $t$ is rep-

\footnotetext{
${ }^{9}$ This simplification is also not necessary, although considering information gathering on both candidates would considerably complicate the model with little value added.

${ }^{10}$ Note that $k$ is just a quality index and does not represent in itself specific sources. We only assume
} 
resented by $w$, while the marginal cost of quality in the information source is $r$. This technology also depends on a vector of individual circumstances $E$ that affect the ability to extract and process information or the capability to use more sophisticated information sources. In empirical terms $E$ includes variables such as education and age and, for practical purposes, I will often refer to this parameter simply as "education". The probability to learn $a_{O}$ finally depends on characteristics of the environment that may affect the availability and reliability of news on the media: I indicate this parameter of information supply with $M$. There is an important difference between $k$ (the source's quality) and $M$ (information supply). The first can be individually chosen, according to each individual's interests and capabilities. $M$ instead is exogenous and determines, for each level of $k$, a shift in the supply of news. I assume that $q(t, k \mid \cdot)$ is always increasing in $E$ and $M$ and make the following assumption ${ }^{11}$ :

Assumption $1 q_{t}>0, q_{k}>0, q_{t E}>0, q_{t M}>0, q_{k E}>0, q_{k M}>0, q_{t t} \leq 0, q_{t t} \times q_{k k}-$ $\left(q_{t k}\right)^{2} \geq 0$

During the electoral campaign citizens acquire information and compare the benefits they would receive from the two candidates. Before the voting stage, citizens can either be informed, if they observe the realization $a_{O}$, or uninformed, if they don't. Informed citizens compare $V\left(a_{I}\right)$ with $V\left(a_{O}\right)$ while the uninformed can only use their prior beliefs $F_{O}(a)$. The benefit from voting is defined as the (expected) difference in utility from the two candidates, taking into account the probability that each voter has to be decisive. In the current analysis I do not consider non-instrumental motivations for either voting or acquiring information. These, however, can be represented as constants, and would therefore not alter our results.

\footnotetext{
that each specific newspaper, magazine, television channel or radio station can be mapped into the space $\mathcal{K}$.

${ }^{11}$ These are standard assumption to be made on any production function to ensure the maximization process is well behaved.
} 
Finally, voting is costly: I represent the cost of voting with $C \in \mathcal{C} \subset \mathbb{R}_{+}$and assume that all voters have the same $C$. Each agent knows $C$. Nothing would change if we assumed that $C$ was distributed across the population according to any distribution function, as long as the distribution of $C$ remains independent of the distribution $F_{O}(a)$.

Finally, one of the two candidates is selected by majority rule and the elected politician implements her preferred policy $a^{*}$. The sequence of events is represented in Figure 1.

Figure 1: Time Line

\begin{tabular}{cccccc}
$0 \mathrm{a}$ & $0 \mathrm{~b}$ & $1 \mathrm{a}$ & $1 \mathrm{~b}$ & $1 \mathrm{c}$ & 2 \\
\hline $\mid$ & $\mid$ & $\mid$ & $\mid$
\end{tabular}

\footnotetext{
0a $=$ Incumbent implements $a_{I}$ and reveals her type

$\mathrm{Ob}=$ Opponent selection from distribution $F(\mathrm{a})$

$1 \mathrm{a}=$ Choice of $t^{*}$ and $k^{*}$ (utility in first period is determined)

$\mathbf{1 b}=$ Realization of $q \rightarrow \widehat{q}$

1c $=$ Election
}

$2=$ Winning candidate implements her preferred policy: utility is realized

\section{Information acquisition and voting}

In this section I first characterize the value and demand for information by backward induction and then restrict the attention on the case of a non-polarized polity by introducing restrictions on prior beliefs and cost of voting.

At time 2 the winning candidate implements her preferred policy: that will be $a_{I}$ if the incumbent is confirmed in office and $a_{O}$ if the opponent candidate wins. For brevity I indicate $V\left(a_{I}\right)$ with $V_{I}$ and eliminate the subscipt from the functions $F(\cdot)$ and $f(\cdot)$, given that $a_{I}$ is known with certainty; where there is no risk of confusion I also use $a$ for the 
opponent's type, eliminating the subscript. $T=1$ indicates the decision to vote (either for $I$ or for $O$ ) and $T=0$ the decision to abstain.

The decision problem of an uninformed citizen at the election stage is then

$$
\max _{T \in\{0,1\}} T\left(P\left|\int\left[V(a)-V_{I}\right] d F(a)\right|-C\right)=\widetilde{W}
$$

where $P$ is the (exogenous) probability to be a decisive voter.

For a citizen who knows the type of the incumbent the problem is instead

$$
\max _{T \in\{0,1\}} T\left(P\left|V(a)-V_{I}\right|-C\right)=W^{*}(a)
$$

The ex ante value of an informed versus an uninformed decision is then given by

$$
\Delta=\int\left[W^{*}(a)-\widetilde{W}\right] d F(a)
$$

At the beginning of period 1 citizens decide about information acquisition. The optimization problem for a generic citizen is:

$$
\begin{array}{rl} 
& \max _{t, k} q(t, k \mid E, M) \Delta-w t-r k \\
\text { s.t. } t \in \mathcal{T} & \mathcal{T} \\
k \in \mathcal{K}
\end{array}
$$

Lemma 1 The expected value of political information is positive, i.e. $\Delta \geq 0$

Proof: See Appendix A.

It is then straightforward to prove the following:

Proposition 1 The optimal functions $t^{*}(E, M, w, r)$ and $k^{*}(E, M, w, r)$ are both increasing in $E, M$ and decreasing in $w, r$. In other terms, the demand for information 
(both the quality of the selected information source and the time devoted to information acquisition) is increasing in education and information supply and decresing in the costs of time and mass media. It is then also true that the probability $Q$ to know a,defined as $q\left(t^{*}, k^{*} \mid E, M\right)=Q(E, M, w, r)$ is increasing in $E$ and $M$ and decreasing in $w$ and $r$.

Assumption 2 Prior beliefs are such that the voters would not vote for any candidate if uninformed, i.e. $P\left|\int\left[V(a)-V_{I}\right] d F(a)\right| \leq C, \forall F \in \mathcal{F}, \forall C \in \mathcal{C}$.

It is now possible to link the probability to be informed to the ex ante probability of voting, i.e. the probability of voting before the actual type of the opponent is revealed. This ex ante perspective is indeed the only one allowed for an external observer, at least if we want to maintain an agnostic view about the actual quality of candidates and their political distance.

In the following I assume that $P\left[V(\bar{a})-V_{I}\right]>C$ and $P\left[V_{I}-V(0)\right]>C$.

Proposition $2 \frac{\partial \operatorname{Pr}(T=1 \mid Q)}{\partial Q} \geq 0$. In other terms, the probability of voting for any candidate is increasing in political knowledge, i.e. in the probability to know the opponent's type.

Proof: see the Mathematical Appendix.

This model links in a very simple way the probability of voting and a number of individual and environmental characteristics, thus providing a theoretical foundation for well established stylized facts on turnout.

\section{Proposition 3}

$\frac{\partial \operatorname{Pr}(T=1 \mid E, M, w, r)}{\partial E} \geq 0, \frac{\partial \operatorname{Pr}(T=1 \mid E, M, w, r)}{\partial M} \geq 0, \frac{\partial \operatorname{Pr}(T=1 \mid E, M, w, r)}{\partial w} \leq 0, \frac{\partial \operatorname{Pr}(T=1 \mid E, M, w, r)}{\partial p} \leq 0$. In other terms, the probability of voting is increasing in education and in information supply and decreasing in the cost of time and the cost of mass media. 
Proof: see the Mathematical Appendix.

The capability to acquire information and the amount of information supplied increase the probability that a citizen votes, ceteris paribus. This explains some common findings of empirical research, like the positive correlation between education and turnout, and at the same time provides a direct link between the probability of turnout and the (exogenous) cost of acquiring information.

\section{$4 \quad$ Ideology}

It is natural to think of ideology in our model in the form of prior beliefs about the opponent candidate ${ }^{12}$. I start by defining ideology according to citizens' beliefs.

Definition 1 (Ideology) An I-leaning ideology (O-leaning ideology), or I-ideology (Oideology), consists of prior beliefs $F($ a) s.t.

$$
\int\left[V(a)-V_{I}\right] d F(a)<0 \quad(\geq 0)
$$

A citizen's ideology is defined only in relation to her beliefs. This, however, does not guarantee that an ideological citizen votes if uninformed: a more stringent definition of ideology would require prior beliefs to be such that, ex ante, the distance between candidates is sufficient to overcome the cost of voting. I introduce therefore the following definition:

Definition 2 (Strong Ideology) A strong I-ideology (O-ideology) consists, for given $P$

\footnotetext{
${ }^{12}$ It is clear that in the real world ideology concerns beliefs about all candidates: however what matters for voting decisions is the perceived position of one candidate relative to the other and to the cost of voting.
} 
and $C$, of prior beliefs $F(a)$ s.t.

$$
\begin{gathered}
P \int\left[V_{I}-V(a)\right] d F(a) \geq C \\
\left(P \int\left[V(a)-V_{I}\right] d F(a) \geq C\right)
\end{gathered}
$$

To compare different degrees of ideology we need a further definition:

Definition 3 Assume citizens $i$ and $j$ have the same $C$ and prior beliefs represented respectively by the distribution functions $F(a)$ and $G(a)$. Then citizen $i$ is more O-ideological (I-ideological) than citizen $j$ if

$$
\int\left[V(a)-V_{I}\right] d F(a)>(<) \int\left[V(a)-V_{I}\right] d G(a)
$$

When we do not want to distinguish between $I$-ideology and $O$-ideology we can simply say that agent $i$ is more ideological than agent $j$.

It should be noted that in the Definitions 1-3, I consider a generic utility function $V(a)$, imposing no restriction on it other than being monotonic nondecreasing. The purpose of the previous definitions is to impose restrictions on the distribution functions rather than on the utility function. Given that we only want to characterize beliefs, independently of preferences, what is required on the functions $F(a)$ and $G(a)$ must be true for any nondecreasing utility function $V(a)$. Now notice that

$$
\int\left[V(a)-V_{I}\right] d F(a)=\int V(a) d F(a)-V_{I}
$$

By requiring Definition 3 to be valid for every non-decreasing function $V(a)$, the comparison of alternative distribution functions based on our definition of ideology is equivalent to using first order stochastic dominance. Under this more restrictive requirement I 
can introduce an indicator of ideology that will be useful in the rest of this section ${ }^{13}$.

Definition 4 Define $\pi$ as an indicator of ideology s.t. an increase in $\pi$ indicates an increase of $\mathrm{O}$-ideology.

Assumption 3 Consider two distribution functions $F_{\pi_{F}}(a)$ and $G_{\pi_{G}}(a)$. Then $\pi_{F}>\pi_{G}$ if and only if $F_{\pi_{F}}(a) \leq G_{\pi_{G}}(a) \forall a$.

As $\pi$ increases, agents become more $O$-ideological or, alternatively, less $I$-ideological. As $|\pi|$ increases we will say that agents become more ideological (without specifying).

It is then possible to divide the set of prior beliefs $\mathcal{F}$ into three groups:

$$
\begin{aligned}
\mathcal{F}_{I} & =\left\{F(a): P \int\left[V_{I}-V(a)\right] d F(a)>C\right\} \\
\mathcal{F}_{O} & =\left\{F(a): P \int\left[V(a)-V_{I}\right] d F(a)>C\right\} \\
\mathcal{F}_{\mathcal{A}} & =\left\{F(a):\left|P \int\left[V(a)-V_{I}\right] d F(a)\right| \leq C\right\} .
\end{aligned}
$$

Accordingly, we can divide the citizens' population $\Omega$ into $\Omega_{I}, \Omega_{O}, \Omega_{A}$, depending on their priors. If uninformed about the true opponent's type, citizens in the set $\Omega_{I}$ vote for the incumbent, citizens in $\Omega_{O}$ vote for the opponent and those in $\Omega_{A}$ abstain. It is important to distinguish this last group from the rest. I refer to citizens in $\Omega_{A}$ as weaklyideological, as opposed to the strong ideological agents in $\Omega_{I}$ and $\Omega_{O}$. We can also define

\footnotetext{
${ }^{13}$ Defining ideological beliefs using first order stochastic dominance seems to make clearer the distinction between private interest and ideology. In a sense, an ideological belief must be independent of preferences (at least as long as we all agree on some basic premise, like that $a$ is a valuable thing). If an individual believes that $F(a)$ stochastically dominates $G(a)$ then he would recommend $F(a)$ to every person with a nondecreasing utility function $V(a)$. This captures the difference between the fact that $F(a)$ is better for the ideological person and the fact that such person believes $F(a)$ to be better for everyone.
} 
$\pi_{-1}, \pi_{0}$, and $\pi_{+1}$ such that

$$
\begin{gathered}
P \int\left[V_{I}-V(a)\right] d F_{\pi_{-1}}(a)=C \\
P \int\left[V_{I}-V(a)\right] d F_{\pi_{0}}(a)=0 \\
P \int\left[V(a)-V_{I}\right] d F_{\pi_{+1}}(a)=C .
\end{gathered}
$$

Then citizens are defined as strongly $I$-ideological when they have $\pi<\pi_{-1}$, weakly $I$-ideological when $\pi_{-1} \leq \pi \leq \pi_{0}$, weakly $O$-ideological when $\pi_{0} \leq \pi \leq \pi_{+1}$, and strongly $O$-ideological when $\pi>\pi_{+1}$. Finally, it is useful to define the following sets, corresponding to possible realizations of the opponent's type:

$$
\begin{aligned}
\mathcal{A}_{I} & =\left\{a: P\left[V(a)-V_{I}\right]<-C\right\} \\
\mathcal{A}_{\Theta} & =\left\{a:-C \leq P\left[V(a)-V_{I}\right] \leq C\right\} \\
\mathcal{A}_{O} & =\left\{a: P\left[V(a)-V_{I}\right]>C\right\}
\end{aligned}
$$

Being referred to realizations, and therefore to the case when the type of the opponent is observed, the sets in (8) do not depend on prior beliefs. Figure 2 shows the partitioning of the opponent's type support in the case in which $V(a)$ is a linear function.

The value of information depends on the decision the citizen would make following only her priors. In particular, information is valuable because it might change the decision taken when uninformed. Consider a strongly $O$-ideological agent. As $\pi$ increases, the probability of realizations in $\mathcal{A}_{I}$ or $\mathcal{A}_{\Theta}$ decreases, thus rendering the possibility of uninformed mistakes less likely. Therefore the value of information should decrease as $\pi$ increases.

For weakly ideological agents we need to introduce a further assumption.

Assumption $4 \pi_{i}>\pi_{j} \Rightarrow \int_{\mathcal{A}_{I} \cup \mathcal{A}_{O}} P\left|V(a)-V_{I}\right|\left[f_{i}(a)-f_{j}(a)\right] d a \geq C \int_{\mathcal{A}_{I} \cup \mathcal{A}_{O}}\left[f_{i}(a)-\right.$ 
Figure 2: Partitioning the $\mathcal{A}$-space

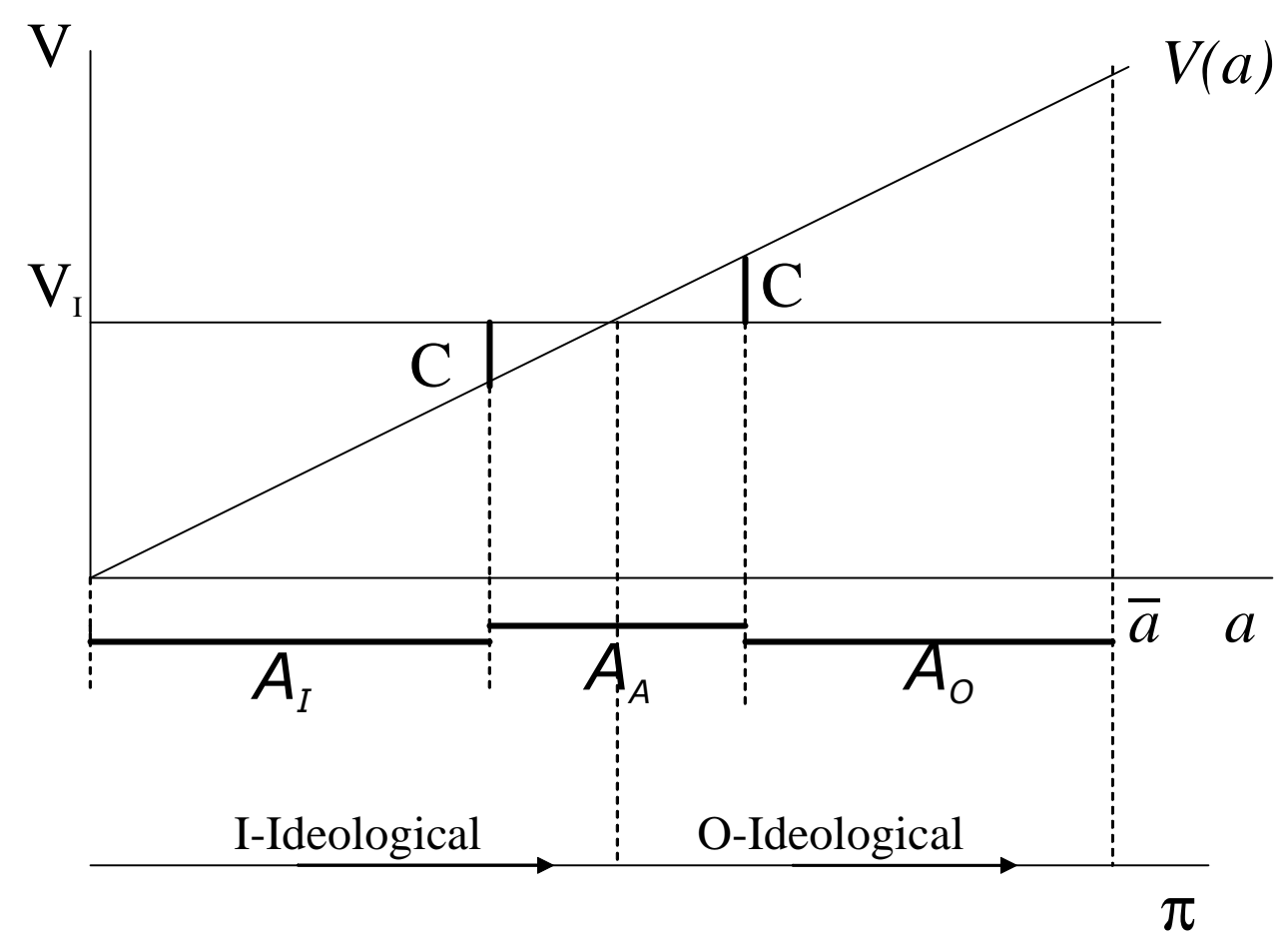

$\left.f_{j}(a)\right] d a$

This assumption is at the same time both a restriction on the distribution functions considered, and a restriction on the possible partitions of the space $\mathcal{A}$. Now consider a weakly $O$-ideological agent, an agent that would abstain if uninformed. In this case an increase in $\pi$ decreases the probability of events in $\mathcal{A}_{I}$; On the other side now the probability of events in $\mathcal{A}_{O}$ increases. We are left therefore with two opposite effects whose overall impact cannot be determined. Assumption 4 basically says that when an agent is $O$-ideological, as $\pi$ increases we expect the increase of likelihood of events in $\mathcal{A}_{O}$ to dominate the corresponding reduction of likelihood of events in $\mathcal{A}_{I}$ (and symmetrically for $I$-ideological agents). 
It is now possible to state our main result.

Proposition 4 Indicate with $\Delta_{F}$ and $\Delta_{G}$ the value of information corresponding respectively to $\pi_{F}$ and $\pi_{G}$. Under Assumptions 1, 3 and 4 and for given $E, M, w, r$, $C$, we have that

$$
\begin{aligned}
\text { 1) } \pi_{G}<\pi_{F}<\pi_{-1} \Rightarrow \Delta_{G}<\Delta_{F} \\
\text { 2) } \pi_{-1} \leq \pi_{G}<\pi_{F}<\pi_{0} \Rightarrow \Delta_{G}>\Delta_{F} \\
\text { 3) } \pi_{0} \leq \pi_{G}<\pi_{F} \leq \pi_{+1} \Rightarrow \Delta_{G}<\Delta_{F} \\
\text { 4) } \pi_{+1}<\pi_{G}<\pi_{F} \Rightarrow \Delta_{G}>\Delta_{F}
\end{aligned}
$$

In other terms, the value of information is first increasing and then, after a threshold, decreasing in ideology. As a consequence, political knowledge is low for extremists and indifferent voters and high at intermediate levels of ideology.

Proof. See the Mathematical Appendix.

Following the foregoing discussion, the intuition for this result has a simple representation in Fig. 3. Citizens that believe there is very little difference between the candidates (compared to the cost of voting) have little benefit from acquiring information: the expected utility from an informed versus an uninformed choice is very limited as not much difference is expected. Citizens who are extremely independent in their evaluation of candidates can therefore be better classified as indifferent: they tend to attach little value to politics in general and therefore remain generally uninformed. As priors become more and more ideological, the demand for information increases, as the value of an informed decision increases too. The value of information reaches its peak for those citizens that are exactly indifferent between voting or not: for such agents observing the realization of $a$ carries a probability 1 of breaking the indifference. Assume for example that agents that are indifferent between abstaing and voting would abstain: there is then a very high probability of a realization occurring in, for example, $\mathcal{A}_{O}$, thus making information 
Figure 3: The Value of Information

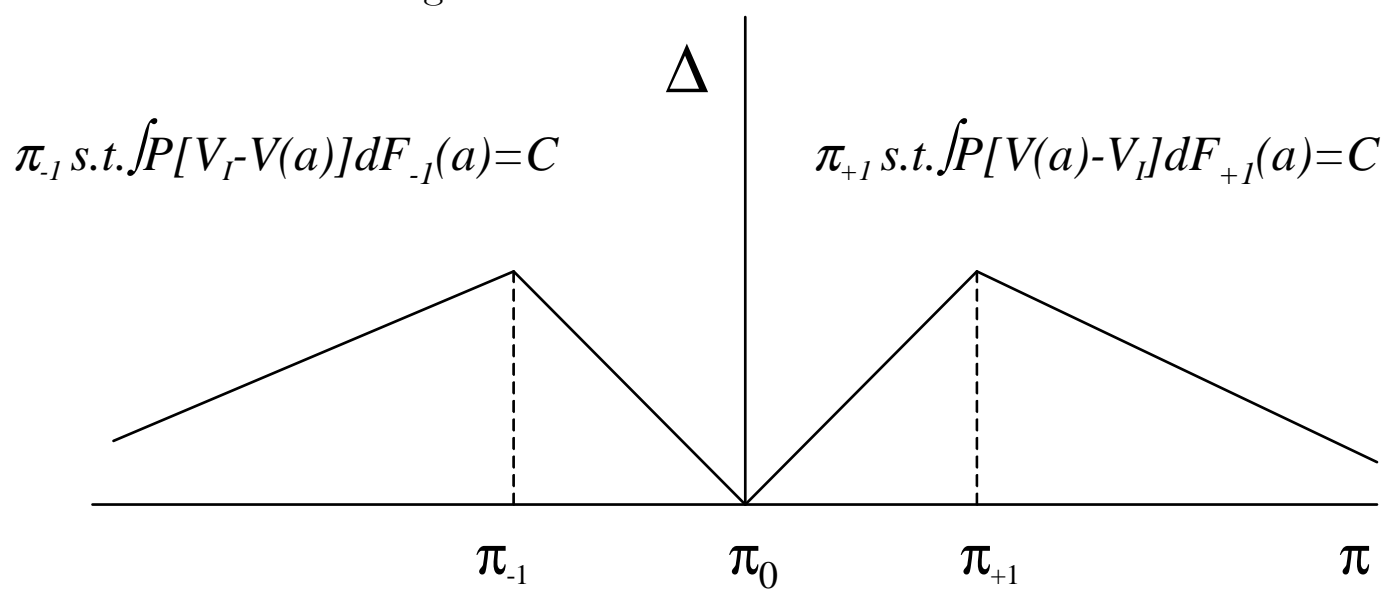

extremely valuable. Citizens in a neighbourhood of this indifference point can be called independent and correspond to the idealized view of a well informed citizen. Starting from this maximum, the value of information decreases monotonically for further increases in ideology. This happens when citizens' priors are strong enough to induce them to vote if uninformed: holding very strong priors means to believe that it is not worth to acquire new information. I will refer to those agents as partisan.

Proposition 4 is stated for a given $C$. However, as $C$ increases we should expect the number of uninformed agents to increase: citizens that, in spite of being sufficiently ideological, have a high cost of voting (think for example of citizens living outside their home country) should remain rationally ignorant.

The remaining of this section links information to turnout.

\section{Proposition 5}

$\frac{\partial \operatorname{Pr}(T=1 \mid Q)}{\partial Q} \geq 0$ for weakly-ideological voters and $\frac{\partial \operatorname{Pr}(T=1 \mid Q)}{\partial Q}<0$ for strongly ideological voters. In other terms, the impact of information on the probability to vote is positive for weakly-ideological voters and negative for strongly ideological voters.

Proof: see the Mathematical Appendix. 
For weakly-ideological voters the situation is analogous to that presented for a nonpartisan polity in Proposition 2: information can only increase the probability of voting for citizens that would otherwise abstain with certainty. Things are just the opposite for partisans: information could lead them to discover that candidates are not as distant as they perceived, thus inducing them not to incur the cost of voting. Thus, the impact of information on turnout depends on the ideological priors of voters ${ }^{14}$.

It is important, at this point, to understand what is the effect of ideology on turnout. As discussed in the introduction, empirical studies tend to show that more ideological voters are more likely to vote and there are many theoretically good reasons to expect this correlation. Here, however, we found that ideology matters also for information acquisition and, in turn, that information matters for turnout. What is the final effect of ideology on turnout? Proposition 6 provides results that take into account the existence of both a direct and an indirect (via information acquisition) effect. Our conclusion is that the indirect effect is not enough to contradict the basic intuition that more ideological citizens are more prone to vote.

Proposition $6 \pi_{F}>\pi_{G}>\pi_{0} \Rightarrow \operatorname{Pr}(O \mid F)>\operatorname{Pr}(O \mid G) ; \pi_{F}<\pi_{G}<\pi_{0} \Rightarrow \operatorname{Pr}(I \mid F)>$ $\operatorname{Pr}(I \mid G)$. If the function $\left|V(a)-V_{I}\right|$ is symmetric around 0 then for any two prior distributions $F(\cdot)$ and $G(\cdot)\left|\pi_{F}\right|>\left|\pi_{G}\right| \Rightarrow \operatorname{Pr}(T=1 \mid F)>\operatorname{Pr}(T=1 \mid G)$. In other terms, a more idelogical voter is more likely to vote.

\section{Proof: see the Mathematical Appendix.}

Before moving to the empirical analysis, it is opportune to spend a few words on the impact of information on the quality of the elected candidate. We proved that weakly ideological citizens increase their likelihood to vote when informed, while strongly ideological ones increase their likelihood to abstain. It is then clear that more information

\footnotetext{
${ }^{14}$ This result appears rather stark. This is due to the fact that, if the signal is received, citizens learn the true type of the opponent. The asymmetric pattern would, however, remain even if citizens could only observe a noisy signal. The important point here is that this result provides a guidance for further empirical investigation. Attention will therefore be devoted to data analysis rather than to refining the model under different hypotheses.
} 
increases the chances to win of the better politician. This result, although derived in a decision-theoretical context, carries implications for the literature on information aggregation that associates better information with a higher likelihood of turnout. Our model delivers such a link but also makes it conditional on voters' prior beliefs. Information is good because, among other things, can induce abstention of otherwise uninformed extremists: this increases the possibility of information aggregation to occur. At the same time, it makes possible to argue that the possibility of information aggregation in elections should be related to a number of individual (often observable) characteristics as well as to specific characteristics of the environment, mainly related to information supply by the mass media.

\section{Empirical evidence from a British election}

Some of the results derived in the previous sections provide rationalizations of observed empirical regularities, others call for new empirical investigations. In this section I therefore provide empirical evidence that shows the compatibility of the theoretical propositions with data. For this purpose I use data from the British Election Study $(\mathrm{BES})^{15}$. The British system is parlamentarian and gives substantial powers to the Prime Minister; the electoral system is first past the post and the parties that realistically contend the possibility to govern are two, the Labour and the Conservative. In this sense, the British system fits our model better than most other political systems. There are nevertheless some features of the electoral system that are not adequately captured by the model and that will be discussed later.

\footnotetext{
${ }^{15}$ I use data on England, Scotland and Wales. The political situation in Northern Ireland is substantially different from the rest of the country as the main cleavage is between the Catholic and Protestant populations rather than on the usual left-right dimension.
} 


\subsection{Data and methods}

I use data from the 1997 general election. The 1997 BES deals with information issues better than any other previous or subsequent BES. Among other questions concerning the election, respondents received in that occasion two sets of questions that can be used to establish how much they know about politics. In a first set of questions they were asked to write down as many candidates' names in their constituency as they could remember (with a maximum of 6 ). In a second set of questions, respondents received 7 statements on the British political and institutional system and were asked to say if they were true or false. Both set of questions have been used to construct a variable (INFO) that is then adopted as a measure of political knowledge ${ }^{16}$. Details on this variable (and on the others) can be found in the Data Appendix.

The other crucial variable is ideology. Two possible measures have been considered. One is the classical left-right self-placement, with zero being the extreme left and 10 the extreme right. I transform this variable by pulling togheter corresponding levels of extremism on both sides. This leads to a measure of ideological strenght (Ideology) that assumes a value of zero if the original left-right variable was 5 (i.e. the respondent places himself in the middle of the ideological spectrum), 1 if it was 4 or $6 \operatorname{etc}^{17}$. The second indicator (Party) measures instead how close respondents feel to their preferred party (if any) and has been built up by combining four separate questions. A full description of the variable Party can be found in the Data Appendix.

Fig. 4 plots average information score by left-right self-placement. It mirrors with

\footnotetext{
${ }^{16}$ Delli Carpini \& Keeter (1996, p.174), in presenting evidence on political knowledge of American voters, based their analysis on nearly 3700 questions collected in various surveys. They concluded that "researchers developing national or general political knowledge scales need not be overly concerned with the mix of specific topics covered by individual items. Scales made up of items tapping only knowledge of institutions and processes, substantive issues, or public figures are likely to serve as reasonable measures of the overarching construct". This is extremely important for us: the empirical analysis presented here is based on a much more limited set of questions and I rely on the assumption that correct answers to such questions are likely to be correlated with knowledge of other issues too. See also Delli Carpini and Keeter (1993).

17 "Don't know" responses have been included among the least ideological category. All regressions have been repeated excluding these observations and the results show only minimal variations. These regressions are available from the authour on request.
} 
surprising similarity the two peaks we described theoretically in Fig. 3. In Fig. 5 I use the partizanship measure where 1 indicates no attachment to any party and 5 maximum attachment to a party. Again, the simple plot of average political knowldege by partizanship mimicks very well our theoretical findings. These plots seem to show that the distribution of information do interact with ideology and partizanship. Before jumping to conclusions, however, it is opportune to use more sophisticated statistical tools and take into account potential correlations with other variables.

I will therefore use regression analysis to estimate both a political knowledge equation and a turnout equation. The first equation to be estimated is

$$
I N F O_{i}=\alpha_{1}^{\prime} \mathbf{X}_{i}+\alpha_{2} I D_{i}+u_{i}
$$

where $I D$ represents ideology or party identification. Suppose there are $K$ types of citizens ranked according to the strenght of their ideological or party attachment. Then $I D$ is a categorical variable and $K-1$ dummies are introduced in the regression. We expect to find a non-monotonic pattern in such dummies, where estimated parameters should first increase with ideology and then decrease (Proposition 4). $\mathbf{X}$ represents a vector of control variables including, among other covariates, education, age, sex and income ${ }^{18}$. The BES data have been matched with Census data to also control for characteristics of the electoral constituency such us socio-economic conditions and electoral closeness ${ }^{19}$. X also includes proxies for information supply and the opportunity cost of time. This gives us an opportunity to test the predictions of Proposition 1. Estimation is by OLS.

To test the predictions of our model for what concens voter turnout the following

\footnotetext{
${ }^{18} \mathrm{~A}$ number of respondents in the BES refused to disclose their income, which forced us to drop a part of the observations. I present regressions both with and without income: in this last case the selection bias is eliminated but at the cost of omitting an important covariate.

${ }^{19}$ In general, I attempt to include most of the variables that, for different reasons, have been considered by the empirical literature on turnout (see for example Matsusaka and Palda, 1999). For this reason the list of variables is quite long, and the standard errors are often high because of multicollinearity. However, this strategy leads to robust results for what concerns our variables of interest and the only risk is that of underestimating the parameters of interest.
} 
equation is estimed by probit:

$$
T_{i}=\beta_{1} I N F O_{i}+\beta_{2}^{\prime} \mathbf{X}_{i}+\beta_{3} I D_{i}+\beta_{4} I D_{i} \times I N F O_{i}+\varepsilon_{i}
$$

In this case $I D$ is treated as a continuous variable, in order to interact it with $I N F O$. Indicating with $\overline{I D}$ the mean of $I D$, Proposition 2 requires that $\beta_{1}+\beta_{4} \overline{I D}>0$ while Proposition 3 places a well defined sign on a number of elements of the vector $\beta_{2}^{\prime}$. For what concerns the interaction between ideology and information, indicating with $\overline{I N F O}$ the average of $I N F O$, I expect $\beta_{3}+\beta_{4} \times \overline{I N F O} \geq 0$ (from Proposition 6 ), and $\beta_{4} \leq 0$ (from Proposition 5). There could be a legitimate concern about the endogeneity of information in the turnout equation. I rely here on the findings of Larcinese (2005), who also uses the 1997 BES data and shows that, when standard controls are introduced in the turnout equation, the omitted variables problem should be of limited relevance and therefore a simple probit regression can be considered sufficiently reliable.

One important question I have left aside at the beginning of this section is how well the model describes the British electoral system. There are at least two important features that are not captured by the model: the first is the division in electoral constituencies, which makes voters choose one of many MPs rather than directly the Prime Minister. The second is the fact that, although there are only two contenders for the place of Prime Minister, there are nevertheless third and local parties that are quite strong in some areas. This means that it is possible to vote strategically; also, it may happen that one of the main contenders on a national scale is not a credible contender at the local level. These features of British elections have certainly an impact on incentives to both be informed and vote. For a number of respondents, incentives might have worked quite differently from how they are depicted in the model. To deal with this possibility I have repeated all the regressions by using a reduced sample in which only observations coming from two-way contests between Labour and Conservatives have been retained. In electoral constituencies where the two main candidates are from the parties that are fighting for the 
government there is little incentive to vote for third parties and the process of information acquisition should be approximately what the model describes. This leads us to exclude more than one third of the observations but, as it will be shown later, has only minor implications for the results.

A more detailed description of the variables is provided in the Data Appendix.

\subsection{Results}

Regression results are reported in the tables from 2 to 5 and provide a rather comfortable picture for what concerns their compatibility with the theoretical model.

Table 2 reports OLS estimates of various specifications of equation (9). In columns 1 and 2 I do not control for income, which gives a larger sample, while in columns 3 and 4 income has been introduced. Columns 1 and 3 use the measure of ideological strenght derived from the respondent's left-right self-placement. The ideology dummies display in both columns the expected pattern: political knowledge increases with ideology, reaches its peak in correspondence of the third group, for which it is also strongly statistically significant, and then declines and becomes statistically indistinguishable from the omitted category (the least ideological). Columns 2 and 4 use party attachment instead of ideological self-placement. The patterns of the coefficients display again a single-peaked shape, with the maximum reached at the fourth category in both columns.

The coefficient of other variables of interest are also reported. First, in conformity with previous findings, better educated and older voters are better informed. To capture the opportunity cost of time, I have used the only piece of information available from the survey, the total number of hours worked, on the assumption that people who work longer hours have a higher cost of devoting time to gathering news. The coefficient obtained for this variable comes with the expected negative sign and is statistically significant (at the $10 \%$ level in column 3 and at the $5 \%$ level in column 4) when I control for income, which is a rather important variable in this case, being obviously correlated with the number of 
hours worked. The effect is not extremely large: an increase of one standard deviation in the number of working hours decreases the information score by less than 0.2 in both columns 3 and 4 of Table 2.

The supply of news also turns out to have a positive effect on political knowledge, with a coefficient which is statistically significant at the $1 \%$ level in columns 1 and 3 and at the $10 \%$ level in columns 2 and 4 . On the aggregate, the effect does not appear to be large: one standard deviation in news supply determines an increase in the information score of 0.05 at most. The standard deviation is, however, not particularly high in this case. The difference between the constituencies with maximum and minimum news supply appears instead sizeable, being equal to 3.3 in the information score.

Table 3 reports the probit estimates of the turnout equation. In all columns both information and ideology come with expected signs and are significant. We intend, however, to have a more stringent test of the model, which constists in a negative sign for the coefficient of the interaction between information and ideology $\left(\beta_{4} \leq 0\right)$. The expected sign is obtained in all specifications, although the coefficient is statistically significant only when party identification is used. In this case we also obtain a larger Pseudo- $R^{2}$, indicating that this variable is better capable at explaining turnout than ideological strenght.

By using the coefficients and the information reported in table 1 (summary statistics) it is also easy to verify that the sign of $\beta_{3}+\beta_{4} \times \overline{I N F O}$ is positive in all cases, which confirms once more the important role of ideology in fostering turnout and the fact that its net impact should always be positive.

One important question concerns the impact of information on turnout. Again, it is easy to verify that the sign of $\beta_{2}+\beta_{4} \times I \bar{D}$ is positive in all columns: other things equal, information increases turnout on average even when controlling for ideology. This result corresponds to the common finding of a positive association between political knowledge and turnout. However, having estimated the interaction term we can now uncover the heterogeneity that hides behind this aggregate result. In fact, while the positive impact of 
information on turnout is rather strong for non-ideological and non-partizan respondents, it becomes negligible or even negative when ideological strenght or party identification reach their peak.

In Tables 4 and 5 I use only observations coming from constituencies with a ConservativeLabour race. Table 4 shows some variations when compared with Table 2 but we still obtain the same non-monotonic patterns in the impact of ideology and partizanship on information. In fact, in this case the impact of party attachment appears stronger, in the sense that everybody is now better informed if compared with the least partizan types. Moreover, the decline associated with the most partizan group is now less pronounced. The weekly number of working hours displays again a negative sign but this time is not statistically significant while the impact of news supply is stronger in columns 1 and 3 and weaker and insignificant in columns 2 and 4 . The turnout estimates in Table 5 only show minimal variations when compared with the results of Table 3, but once again the impact of party attachment on turnout appears stronger. Overall, it appears that party attachment has a larger relevance in Conservative-Labour constituencies while other factors become less important.

\section{Concluding remarks}

People learn if they have the motivation, the ability, and the opportunity to do so. There seems to be little motivation for political information acquisition by voters: as for many other situations involving collective action problems, voter turnout and information acquisition in elections are complex social phenomena that are hard to explain with any single-handed approach. It is, nevertheless, possible to make some progress when the focus on motivation is replaced by a focus on opportunity and ability: although motivations to vote and to be informed clearly come from individual, often unobservable, characteristics, the opportunity and the ability to learn will eventually leave their mark on the amount and the type of political knowledge that citizens possess. Although not 
an exhaustive explanation, this methodology allows us to perform some interesting comparative statics in oder to derive novel testable propositions. This is the approach taken in this work, where I try to link political knowledge and turnout with observable constraints and individual characteristics by developing a testable decision-theoretical model of information acquisition and voting.

In this model citizens "produce" their own information by using mass media and time according to a personal technology that reflects their ability to acquire, process and retain information. The parameters that determine different productivities in information acquisition are then represented by relevant individual characteristics (like education, income and age) as well as by the supply of information, in the form of mass media coverage of political issues. This theoretical analysis leads to testable propositions about the links of individual and environmental characteristics with citizens' political knowledge.

It is important, however, to distinguish the flow of information received during an electoral campaign from the prior stock of political "knowledge" (prior beliefs). Such knowledge is the outcome of individual history, from parents' influence to other forms of socialization and direct personal experiences. Not surprisingly, the perception of political matters is generally very diverse across the population. I show that such diversity also plays a role in the decision to acquire information and, then, in the impact that political knowledge may have on turnout. In particular, the least informed citizens are, other things equal, those with the weakest and the strongest ideological beliefs. In the first case, agents are ex ante so indifferent between the candidates that the expected benefit of acquiring information does not cover its costs: Thus, in contrast to what intuition would suggest, extremely "independent" citizens can be far from the ideal that a participative vision of democracy requires. On the other side, people with extreme prior beliefs are confident enough in their opinions and do not find it useful to acquire information. Thus, slightly ideological citizens turn out to be the most informed: This is a way in which a moderate amount of ideological polarization can be useful to the functioning of democratic 
institutions.

The model presented is compatible with most typical results of empirical research, like the positive effect of education on participation. Moreover, through the interaction between ideology and information, we are able to derive new testable predictions: of particular relevance is the fact that information should have a positive impact on turnout only for non-ideological voters.

Finally, since voters with strong priors make less-dependable choices, this result argues in favour of the importance of information for good collective decision-making and the accountability of public officials. One possible objection to this step is that this model avoids the complications that arise when strategic voting is considered. However, whether the vast literature on strategic turnout has delivered any practical insight into our understanding of political elections remains still unclear. This literature relies on the idea that voting decisions should be made conditional on the probability of each voter to be pivotal: In large elections (as opposed, for example, to a committee or a jury ${ }^{20}$ ) this sort of strategic behaviour appears very unlikely and would require a degree of sophistication that no voter has any incentive to develop in the first place. A simpler decision-theoretical framework seems more approriate in that it limits the rationality of voters in a well defined way. The alternative offered by models with bounded rationality often incur in the problem of determining where rationality should end and how it should be replaced.

Some empirical evidence on these theoretical results is provided from the 1997 general election in the United Kingdom. The results confirm most of the theoretical intuitions. Individual and environmental characteristics generally come with the expected signs. For some variables (like age and education) this is just a further confirmation in a well established empirical literature. Other variables have instead been identified thanks to

\footnotetext{
${ }^{20}$ Before being extended to large electorates, the literature on information aggregation aimed at explaining the decision-making process of a jury with a common objective function. This is context in which the celebrated Condorcet-jury theorem can be proved. Austen-Smith and Banks (1996) make the point that sincere voting does not constitute a Nash equilibrium with majority voting. Persico (2004) provides the first model of this sort with information acquisition and compares the properties of different decision rules.
} 
the model: People who work longer hours are, ceteris paribus, less informed on political matters and information supply on the press tends to increase political knowledge. As predicted by our model, the relationship between political knowledge and ideological strenght has an inverted U-shape. The empirical analysis also confirms that ideology and information interact in significant ways in their impact on turnout. Both ideology and information display positive correlations with turnout. However, these well established empirical regularities hide an important heterogeneity which, in the empirical analysis, is captured by an interaction term: For more ideological voters the positive impact of information on turnout is reduced. This effect is found in the case of party identification but not when left-right self-placement is used. Further investigation, beyond the scope of this paper, should explore the reason for this difference, probably due to the relationship between ideology and partisanship in the British context.

This analysis has consequences for the way to think of the role of information and mass media in democratic systems. Overall, our findings show that information matters for electoral behavior. However, because of its relation with ideology, information acquisition in a polarized polity is limited, and ideology rather than information determine policy outcomes. The same can happen to an extremely non-polarized population, with a prevalence of indifferent voters. Thus, a limited amount of polarization helps reaching informed outcomes. In this process, mass media and voters' personal resources play a crucial role: Formally democratic institutions might be emptied of substantial content if accurate political information is either unavailable or beyond most voters' reach.

\section{References}

[1] Achen, C.H. (1992): Social Psychology, Demographic Variables, and Linear Regression: Breaking the Iron Triangle in Voting Research, Political Behaviour, 14, n.3, 195-211. 
[2] Austen-Smith, D. and J. Banks (1996): Information aggregation, rationality, and the Condorcet jury theorem. American Political Science Review, 90, 34-45.

[3] Bartels, L.M. (2000): Partisanship and Voting Behaviour, 1952-1996. American Journal of Political Science, 44, n.1, 35-50.

[4] Bartle, J. (1998): Left-Right Position Matters, but Does Social Class? Causal Models of the 1992 British General Election, British Journal of Political Science, 28, 501-529.

[5] Becker, G. (1965): A Theory of the Allocation of Time. Economic Journal, 75, 493-517.

[6] Berelson, B.R., P.F. Lazarsfeld and W.N. McPhee (1954): Voting. Chicago: The University of Chicago Press.

[7] Besley, T. and R. Burgess (2002): The Political Economy of Government Responsiveness: Theory and Evidence from India, Quarterly Journal of Economics, 117(4), $1415-1452$.

[8] Besley, T. and A. Prat (2005): Handcuffs for the grabbing hand? Media capture and government accountability, STICERD DP in Political Economy and Public Policy, 7.

[9] Campbell, A., P.E. Converse, W.E. Miller and D.E. Stokes (1960): The American Voter. New York: John Wiley \& Sons.

[10] Delli Carpini, M.X. and S. Keeter (1993): Measuring Political Knowledge: Putting First Things First, American Journal of Political Science, 37, n. 4, 1179-1206.

[11] Delli Carpini M.X. and S. Keeter (1996): What Americans Know about Politics and Why It Matters, Yale University Press.

[12] Denver, D. (2003): Elections and Voters in Britain, Palgrave MacMillan. 
[13] Erikson, R.S., G.C. Wright and J.P. McIver (1993): Statehouse Democracy: Public Opinion and Policy in the American States. Cambridge University Press.

[14] Feddersen, T.J. and W. Pesendorfer (1996): The Swing's Voter's Curse, American Economic Review, 86, 408-424.

[15] Feddersen, T.J. and W. Pesendorfer (1999): Abstention in Elections with Asymmetric Information and Diverse Preferences, American Political Science Review, 93, 381-398.

[16] Gerber, A. and D.P Green (1998): Rational Learning and Partisan Attitudes, American Journal of Political Science, 42, n. 3, 794-818.

[17] Heath, A., R. Jowell and J.K. Curtis (1985): How Britain Votes, Oxford: Pergamon Press.

[18] Heath, A., R. Jowell, J.K. Curtice and P. Norris (1999): The British General Election Study, 1997, available at http://www.data-archive.ac.uk/.

[19] Larcinese, V. (2005). Does Political Knowledge Increase Turnout? Evidence from the 1997 British General Election, STICERD Discussion Paper in Political Economy and Public Policy, 1.

[20] Lassen, D.D. 2005. The Effect of Information on Voter Turnout: Evidence from a Natural Experiment. American Journal of Political Science, 49(1), 103-118.

[21] Lazarsfeld, P., B. Berelson and H. Gaudet (1944): The people's choice. New York: Columbia University Press.

[22] Lupia, A. and M.D. McCubbins (1998): The Democratic Dilemma: Can Citizens Learn What They Need to Know? New York: Cambridge University Press.

[23] Matsusaka, J.G. (1995): Explaining Voter Turnout Patterns: an Information Theory, Public Choice, 84, 91-117. 
[24] Matsusaka, J.G. and F. Palda (1999): Voter Turnout: How Much Can we Explain?, Public Choice, 98, 431-446.

[25] Miller, W.E and J.M.Shanks (1996): The New American Voter, Cambridge MA: Harvard University Press.

[26] Milligan, K., E. Moretti and P. Oreopoulos. 2004. Does Education Improve Citizenship? Evidence from the US and the UK. Journal of Public Economics 88: $1667-1695$.

[27] Norris, P (2001): The British Parliamentary Constituency Database, 1992-2001. Available at http://ksghome.harvard.edu/ pnorris/Data/Data.htm.

[28] Palfrey, T.R.and K.T. Poole (1987): The Relationship Between Information, Ideology, and Voting Behavior, American Journal of Political Science, 31, 511-530.

[29] Persico, N. (2004): Committee Design with Endogenous Information. The Review of Economic Studies, 71(1), 165-94.

[30] Popkin, S.L. (1991): The Reasoning Voter. Chicago: The University of Chicago Press.

[31] Riker, W.H. and P.C. Ordeshook (1968): "A Theory of the Calculus of Voting", American Political Science Review, 62, 25-42.

[32] Rosenstone, S.J. and Hansen, J.M. (1993): Mobilization, Participation, and Democracy in America. New York: McMillan Publishing Company.

[33] Sanders, M.S. (2001): "Uncertainty and Turnout", Political Analysis, 9, 45-57.

[34] Wittman, D.A. (1995): The myth of democratic failure: why political institutions are efficient. Chicago: University of Chicago Press.

[35] Wolfinger R.E. and Rosenstone, S.J. (1980): Who Votes? New Haven: Yale University Press. 


\section{Mathematical Appendix}

Proof of Lemma $1 \Delta=\int\left[W^{*}(a)-\widetilde{W}\right] f(a) d a$.

Remember that

$$
W^{*}(a)=\max _{\{T\}} T\left(P\left|V(a)-V_{I}\right|-C\right)
$$

and define

$$
W^{*}=\max \left\{0, P \int\left|V(a)-V_{I}\right| f(a) d a-C\right\}
$$

Also

$$
\left.\widetilde{W}=\max _{\{T\}} T P\left|\int\left[V(a)-V_{I}\right] f(a) d a\right|-C\right)
$$

which means

$$
\widetilde{W}=\max \left\{0, P\left|\int\left[V(a)-V_{I}\right] f(a) d a\right|-C\right\}
$$

For $\Delta$ to be positive it is sufficient to prove that

$$
\max \left\{0, \int\left|V(a)-V_{I}\right| f(a) d a-C, 0\right\} \geq \max \left\{0,\left|\int\left[V(a)-V_{I}\right] f(a) d a\right|-C\right\}
$$

If we define

$$
\begin{aligned}
& \mathcal{A}_{-}=\left\{a:\left[V(a)-V_{I}\right]<0\right\} \\
& \mathcal{A}_{+}=\left\{a:\left[V(a)-V_{I}\right] \geq 0\right\}
\end{aligned}
$$

then it is clear that

$$
\begin{aligned}
\int\left|V(a)-V_{I}\right| f(a) d a & =\int_{\mathcal{A}_{+}}\left[V(a)-V_{I}\right] f(a) d a+\int_{\mathcal{A}_{-}}\left[V_{I}-V(a)\right] f(a) d a \\
\left|\int V(a)-V_{I} f(a) d a\right| & =\left|\int_{\mathcal{A}_{+}}\left[V(a)-V_{I}\right] f(a) d a-\int_{\mathcal{A}_{-}}\left[V_{I}-V(a)\right] f(a) d a\right|
\end{aligned}
$$


from which

$$
\int\left|V(a)-V_{I}\right| f(a) d a-C \geq\left|\int\left[V(a)-V_{I}\right] f(a) d a\right|-C
$$

If $P \int\left|V(a)-V_{I}\right| f(a) d a \leq C$ then $W^{*}=0$. But then A1 implies that $\mid \int[V(a)-$ $\left.V_{I}\right] f(a) d a \mid \leq C$ and therefore $\widetilde{W}=0$.

Proof of Proposition 2 Let us indicate with $\widehat{q} \in\{0,1\}$ the fact of being ex post informed $(\widehat{q}=1)$ or not $(\widehat{q}=0)$. For an uninformed citizen we have

$$
\operatorname{Pr}(T=1: \widehat{q}=0)=0
$$

while for an (ex post) informed citizen, the probability to vote (ex ante) is

$$
\begin{aligned}
\operatorname{Pr}(T & =1: \widehat{q}=1)=\operatorname{Pr}\left(a:\left|\left[V(a)-V_{I}\right]\right|-C>0\right) \\
& =\int_{\mathcal{A}_{I}} d F(a)+\int_{\mathcal{A}_{O}} d F(a) \geq 0
\end{aligned}
$$

where $\mathcal{A}_{I}$ and $\mathcal{A}_{O}$ are the sets defined in (8).

If $P\left[V(\bar{a})-V_{I}\right]>C$ and $P\left[V_{I}-V(0)\right]>C$ then $\operatorname{Pr}(T=1 \mid \widehat{q}=1)>0$.

The probability to vote is then given by the probability to be informed multiplied by the probability to vote when informed, i.e.

$$
\operatorname{Pr}(T=1 \mid Q)=Q \operatorname{Pr}(T=1 \mid \widehat{q}=1)
$$

from which the result follows immediately.

Proof of Proposition 3 From the A2 we have that

$$
\operatorname{Pr}(T=1 \mid E, M, w, r)=Q(E, M, w, r) \operatorname{Pr}(T=1 \mid \widehat{q}=1)
$$


We also know from Proposition 1 that

$$
\frac{\partial Q(E, M, w, r)}{\partial E} \geq 0
$$

from which it follows that

$$
\frac{\operatorname{Pr}(T=1 \mid E, M, w, r)}{\partial E}=\frac{\partial Q(E, M, w, r)}{\partial E} \times \operatorname{Pr}(T=1 \mid \widehat{q}=1) \geq 0
$$

Similarly we can prove the rest of the proposition

Proof of Proposition 4 Let us focus on the positive part of the diagram in Figure 3. Cases 3) and 4) refer respectively to weak and strong $O$-ideologies. This analysis applies simmetrically to cases 1) and 2) (respectively strong and weak $I$-ideologies). Consider first a weakly $O$-ideological citizen. The value of information in such case is given by the probability information will induce a switch to a vote for I plus the probability it will induce a vote for $O$, i.e.

$$
\Delta=\int_{\mathcal{A}_{I}}\left(P\left[V_{I}-V(a)\right]-C\right) d F(a)+\int_{\mathcal{A}_{O}}\left(P\left[V(a)-V_{I}\right]-C\right) d F(a)
$$

Given two distributions $F$ and $G$ we want to prove that $\pi_{F}>\pi_{G} \Rightarrow \Delta_{F}>\Delta_{G}$ i.e.

$$
\begin{aligned}
& \int_{\mathcal{A}_{I}}\left(P\left[V_{I}-V(a)\right]-C\right) d F(a)-\int_{\mathcal{A}_{I}}\left(P\left[V_{I}-V(a)\right]-C\right) d G(a)+ \\
& \int_{\mathcal{A}_{O}}\left(P\left[V(a)-V_{I}\right]-C\right) d F(a)-\int_{\mathcal{A}_{O}}\left(P\left[V(a)-V_{I}\right]-C\right) d G(a) \\
> & 0
\end{aligned}
$$


Define $s(a)=\left[V(a)-V_{I}\right]$. Assumption 4 implies

$$
\begin{aligned}
& -\int_{\mathcal{A}_{I}} \operatorname{Ps}(a)[f(a)-g(a)] d a-\int_{\mathcal{A}_{I}} C[f(a)-g(a)] d a \\
& +\int_{\mathcal{A}_{O}} P s(a)[f(a)-g(a)] d a-\int_{\mathcal{A}_{O}} C[f(a)-g(a)] d a \\
> & 0
\end{aligned}
$$

$\Rightarrow$

$$
\begin{aligned}
& -\int_{\mathcal{A}_{I}} P s(a) d F(a)-\int_{\mathcal{A}_{I}} C d F(a) \\
& +\int_{\mathcal{A}_{I}} P s(a) d G(a)+\int_{\mathcal{A}_{I}} C d G(a)+ \\
& \int_{\mathcal{A}_{O}} P s(a) d F(a)-\int_{\mathcal{A}_{O}} C d F(a) \\
& \quad-\int_{\mathcal{A}_{O}} P s(a) d G(a)+\int_{\mathcal{A}_{O}} C d G(a) \\
& >0
\end{aligned}
$$

$\Rightarrow A 3$

Now consider a strongly $O$-ideological citizen. The value of information is in this case given by:

$$
\Delta=\int_{\mathcal{A}_{I}} 2 P\left[V_{I}-V(a)\right] d F(a)+\int_{\mathcal{A}_{\Theta}}\left(P\left[V_{I}-V(a)\right]+C\right) d F(a)
$$

i.e. the value due to a potential shift to a change in favour of $I$ plus the value due to a shift in favour of abstention. Now we want to prove that $\pi_{F}>\pi_{G} \Rightarrow \Delta_{F}<\Delta_{G}$ i.e.

$$
\begin{aligned}
& \int_{\mathcal{A}_{I}} 2 P\left[V_{I}-V(a)\right] d F(a)+\int_{\mathcal{A}_{\Theta}}\left(P\left[V_{I}-V(a)\right]+C\right) d F(a)- \\
& \left.-\int_{\mathcal{A}_{I}} 2 P\left[V_{I}-V(a)\right]\right) d G(a)-\int_{\mathcal{A}_{\Theta}}\left(P\left[V_{I}-V(a)\right]+C\right) d G(a) \\
& <0
\end{aligned}
$$


It is useful to adopt the following notation:

$$
\begin{aligned}
& \mathcal{A}_{I}=[\underline{a}, \widehat{a}] \\
& \mathcal{A}_{\Theta}=[\widehat{a}, \widehat{\widehat{a}}] \\
& \mathcal{A}_{O}=[\widehat{\widehat{a}}, \bar{a}]
\end{aligned}
$$

Integrating the A4 by parts we get:

$$
\begin{aligned}
& 2 P\left[V_{I}-V(\widehat{a})\right] F(\widehat{a})-2 P\left[V_{I}-V(\underline{a})\right] F(\underline{a})+\int_{\mathcal{A}_{I}} 2 P V^{\prime}(a) F(a) d a+ \\
& +\left(P\left[V_{I}-V(\widehat{\widehat{a}})\right]+C\right) F(\widehat{\widehat{a}})-\left(P\left[V_{I}-V(\widehat{a})\right]+C\right) F(\widehat{a})+\int_{\mathcal{A}_{\Theta}} P V^{\prime}(a) F(a) d a- \\
& -2 P\left[V_{I}-V(\widehat{a})\right] G(\widehat{a})+2 P\left[V_{I}-V(\underline{a})\right] G(\underline{a})-\int_{\mathcal{A}_{I}} 2 P V^{\prime}(a) G(a) d a- \\
& -\left(P\left[V_{I}-V(\widehat{\widehat{a}})\right]+C\right) G(\widehat{\widehat{a}})+\left(P\left[V_{I}-V(\widehat{a})\right]+C\right) G(\widehat{a})-\int_{\mathcal{A}_{\Theta}} P V^{\prime}(a) G(a) d a
\end{aligned}
$$

Now notice that

$$
\begin{aligned}
& 2 P\left[V_{I}-V(\underline{a})\right] F(\underline{a})=2 P\left[V_{I}-V(\underline{a})\right] G(\underline{a})=0 \\
& P\left[V_{I}-V(\widehat{a})\right]=C \\
& P\left[V_{I}-V(\widehat{\widehat{a}})\right]=-C .
\end{aligned}
$$

We are left with

$$
\begin{aligned}
& 2 C F(\widehat{a})+\int_{\mathcal{A}_{I}} 2 P V^{\prime}(a) F(a) d a \\
& -(C+C) F(\widehat{a})+\int_{\mathcal{A}_{\ominus}} P V^{\prime}(a) F(a) d a- \\
& -2 C G(\widehat{a})-\int_{\mathcal{A}_{I}} 2 P V^{\prime}(a) G(a) d a- \\
& +(C+C) G(\widehat{a})-\int_{\mathcal{A}_{\Theta}} P V^{\prime}(a) G(a) d a
\end{aligned}
$$


Therefore

$$
\begin{aligned}
\Delta_{F}-\Delta_{G}= & \int_{\mathcal{A}_{I}} 2 P V^{\prime}(a)[F(a)-G(a)] d a+ \\
& \int_{\mathcal{A}_{\Theta}} P V^{\prime}(a)[F(a)-G(a)] d a
\end{aligned}
$$

But $F(a) \leq G(a) \forall a$ which implies $\Delta_{F} \leq \Delta_{G}$

Proof of Proposition 5 The proof in the case of weakly-ideological citizens proceeds along the lines of the proof of proposition 2 .

When agents are strongly-ideological we have, for uninformed citizens

$$
\operatorname{Pr}(T=1 \mid \widehat{q}=0)=1
$$

while for an (ex post) informed citizen, the probability (ex ante) to vote is

$$
\begin{aligned}
1 & >\operatorname{Pr}(T=1 \mid \widehat{q}=1)=\operatorname{Pr}\left(a \mid a \in \mathcal{A}_{I} \cup \mathcal{A}_{O}\right)= \\
& =\int_{\mathcal{A}_{I} \cup \mathcal{A}_{O}} d F(a)>0
\end{aligned}
$$

Note that the probability to vote conditional on being informed is the same both for strongly and weakly ideological citizens.

The probability to vote is then given by the probability to be informed multiplied by the probability to vote when informed, i.e.

$$
\begin{aligned}
\operatorname{Pr}(T & =1 \mid Q)=Q \operatorname{Pr}(T=1 \mid \widehat{q}=1)+(1-Q) \operatorname{Pr}(T=1 \mid \widehat{q}=0) \\
& =1-Q(1-\operatorname{Pr}(T=1 \mid \widehat{q}=1))
\end{aligned}
$$

Proposition 5 follows from the fact that $\operatorname{Pr}(T=1 \mid \widehat{q}=1)<1$ 
Proof of Proposition 6 The probability of voting under the distribution function $F$ is:

$$
\left.\operatorname{Pr}(T=1 \mid F)=Q_{F} \operatorname{Pr}(T=1 \mid \widehat{q}=1)+\left(1-Q_{F}\right) \operatorname{Pr}(T=1 \mid \widehat{q}=0)\right)
$$

Consider two weakly O-ideological distributions $F$ and $G$ s.t. $\pi_{F}>\pi_{G}$. Then $\Delta_{F}>\Delta_{G}$ and $Q_{F}>Q_{G}$. Thus

$$
\operatorname{Pr}(T=1 \mid F)=Q_{F} \operatorname{Pr}(T=1 \mid \widehat{q}=1)>Q_{G} \operatorname{Pr}(T=1 \mid \widehat{q}=1)=\operatorname{Pr}(T=1 \mid G)
$$

If instead $F, G \in \mathcal{F}_{O}$ then

$$
\begin{aligned}
& \operatorname{Pr}(T=1 \mid F)=1-Q_{F}[1-\operatorname{Pr}(T=1 \mid \widehat{q}=1)] \\
& \operatorname{Pr}(T=1 \mid G)=1-Q_{G}[1-\operatorname{Pr}(T=1 \mid \widehat{q}=1)]
\end{aligned}
$$

Now $\pi_{F}>\pi_{G} \Rightarrow Q_{F}<Q_{G}$. Since $1-\operatorname{Pr}(T=1 \mid \widehat{q}=1)>0$ we get that $\operatorname{Pr}(T=$ $1 \mid F)>\operatorname{Pr}(T=1 \mid G)$.

The same applies to $I$-ideological agents. Now notice that, if $\left|V(a)-V_{I}\right|$ is symmetric around zero, then we can compare $I$-ideological with $O$-ideological agents and derive that $\left|\pi_{F}\right|>\left|\pi_{G}\right| \Rightarrow \operatorname{Pr}(T=1 \mid F)>\operatorname{Pr}(T=1 \mid G)$ 


\section{Data Appendix}

In all regressions I use some control variables whose coefficients are not reported in the tables and whose denomination is sufficiently self-explanatory: these variables are age, married, sex, church attendance (categorical variable), income(categorical variable), farmer, asian, black, lenght of residence in the constituency, houseowner, contacted by a canvasser during the electoral campaign, contacted by phone, voted in the previous election, regular reader of a quality newspaper, type of economic activity (categorical variable), union member, UK standard region (categorical variable). The precise definition of these variables can easily be found in the British Election Study 1997 (BES) and therefore will not be discussed in this appendix. Other standard controls are taken from the 1991 Census and include district unemployment rate and population percentage in the district with a university degree. Finally, I include in all regressions the marginality of the constituency, calculated as $\frac{W-R}{W+R}$, where $W$ and $R$ are the percentage of votes reported respectively by the winning candidate and the runner up (the original data are taken from Pippa Norris' British Constituency Database).

I report below the precise definition of the the most important variables used in the regressions.

\section{- Information}

The variable Information has been constructed by using the following two BES questions:

1. Do you happen to remember the names of any candidates who stood in your constituency in the general election this year?

Please write in all the names of candidates that you can remember (6 spaces provided) or tick box: I can't remember any of the candidates' names.

Note: the names of candidates written in by respondents were checked against official lists of candidates. 
2. Political knowledge quiz (answers: true/false/don't know):

a: Margaret Thatcher was a Conservative Prime Minister;

$\mathrm{b}$ : The number of MP is about 100;

c: The longest time allowed between general elections is four years;

d: Britain's electoral system is based on proportional representation;

e: MPs from different parties are on parliamentary committees;

f: Britain has separate elections for the European parliament and the British parliament;

g: No-one may stand for parliament unless they pay a deposit.

Let us define with names the number of candidates correctly reported and with quiz the number of correct answers in question 2. INFO is then given by

$$
I N F O=\text { names }+0.66 \times q u i z
$$

The reason quiz has been downweighted is due to the fact that being true /false questions, it was possible for respondents to guess the answer without really knowing it, while this is not possible for names. Therefore, using Bayes' rule we have (assuming the prior probability of a correct answer is 0.5$)$ :

$$
\operatorname{Pr}(\text { know } \mid \text { correct })=\frac{\operatorname{Pr}(\text { correct } \mid \text { know })}{\operatorname{Pr}(\text { correct } \mid \text { know })+\operatorname{Pr}(\text { correct } \mid \text { don't })}=\frac{1}{1+0.5}=0.66
$$

- Turnout. Dummy variable equal to 1 if the responded voted in the 1997 election (verified for most observations).

- Hours. Derived from answers to the following question: "How many hours (do/will/did) you normally work a week in your main job, including any paid or unpaid overtime?".

- Ideology. Derived from answers to the following question:

"In politics people sometimes talk of left and right. Where would you place yourself on a scale from 0 to 10 , where 0 means the left and 10 means the right?" 
Ideology is then equal to 1 if the answer is 5 , to 2 if the answer is 4 or 6 , to 3 if the answer is 3 or 7 etc. Respondents who answered "can't choose" are excluded.

- Party-identification. Based on three questions.

1. "Do you generally think of yourself as a little closer to one of the parties than the others? If yes, which party?". Outcome: a) no; b) yes $\rightarrow$ [party named].

2. "Would you call yourself [party named] very strong, fairly strong or not very strong?

3. "Which one of the reasons on this card comes closest to the main reason you voted for the party you chose?"

Then Party-identification is a categorical variable that assumes the following values:

Party-identification $=1$ if the answer to question 1 is "no" or "don't know".

Party-identification $=2$ if the answer to question 2 is "not very strong" or "don't know".

Party-identification $=3$ if the answer to question 2 is "fairly strong".

Party-identification $=4$ if the answer to question 2 is "very strong".

Party-identification $=5$ if the answer to question 2 is "very strong" and the answer to question 3 is "I always vote that way".

- Salience. This variable is based on articles collected from three national newspapers (The Guardian, The Independent and The Times) during the last 30 days of the electoral campaign. First, the total number of articles mentioning one of the candidates has been collected (by newspaper and by electoral constituency). These numbers have been weighted by the inverse of the total political articles appeared in each newspaper during the same period. The variable Salience is then the average (across the three newspapers) of the weighted number of articles appeared about a candidate in the electoral constituency. 
Fig.4: Information score by left-right self-placement

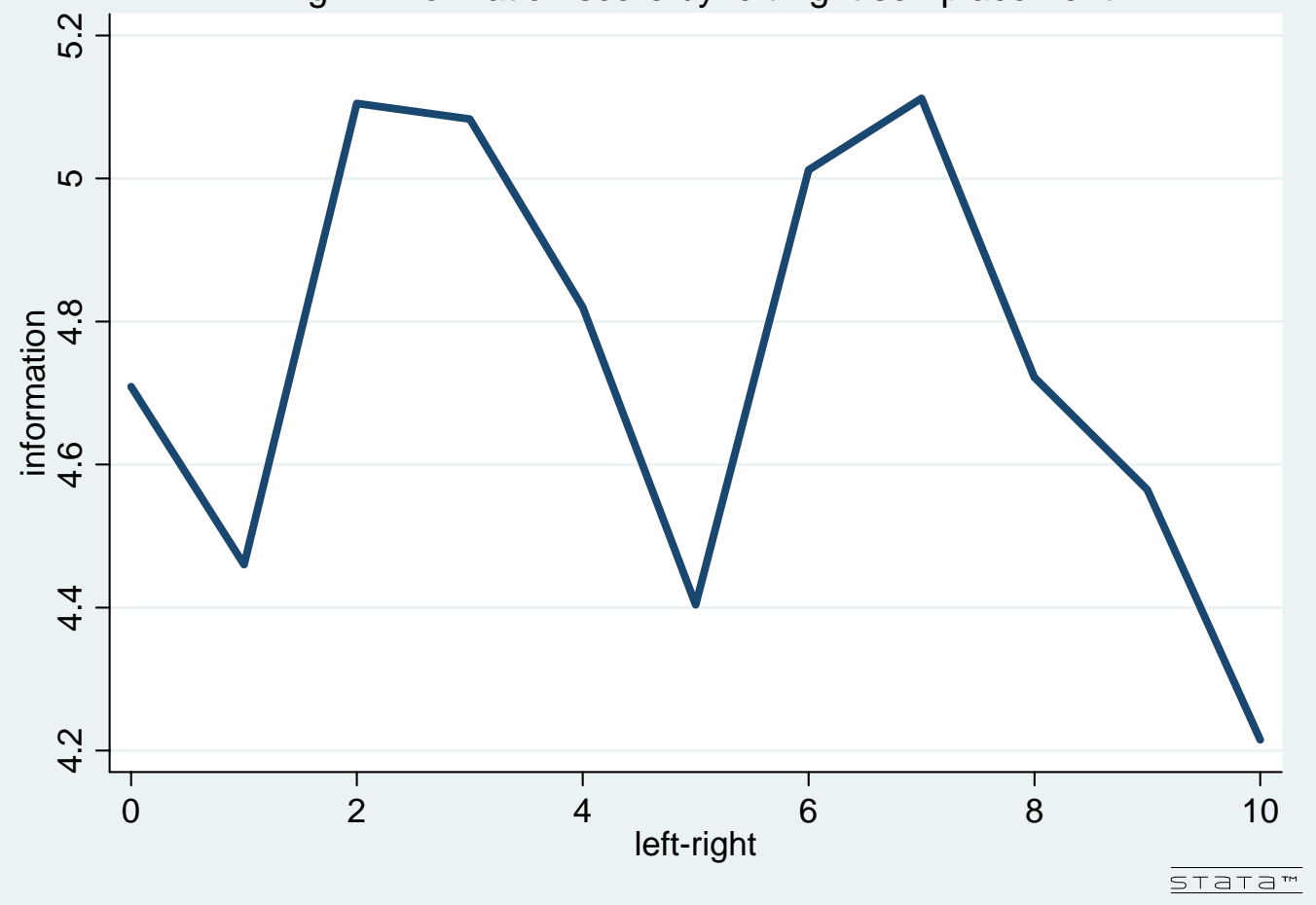


Fig.5: Information score by party attachment

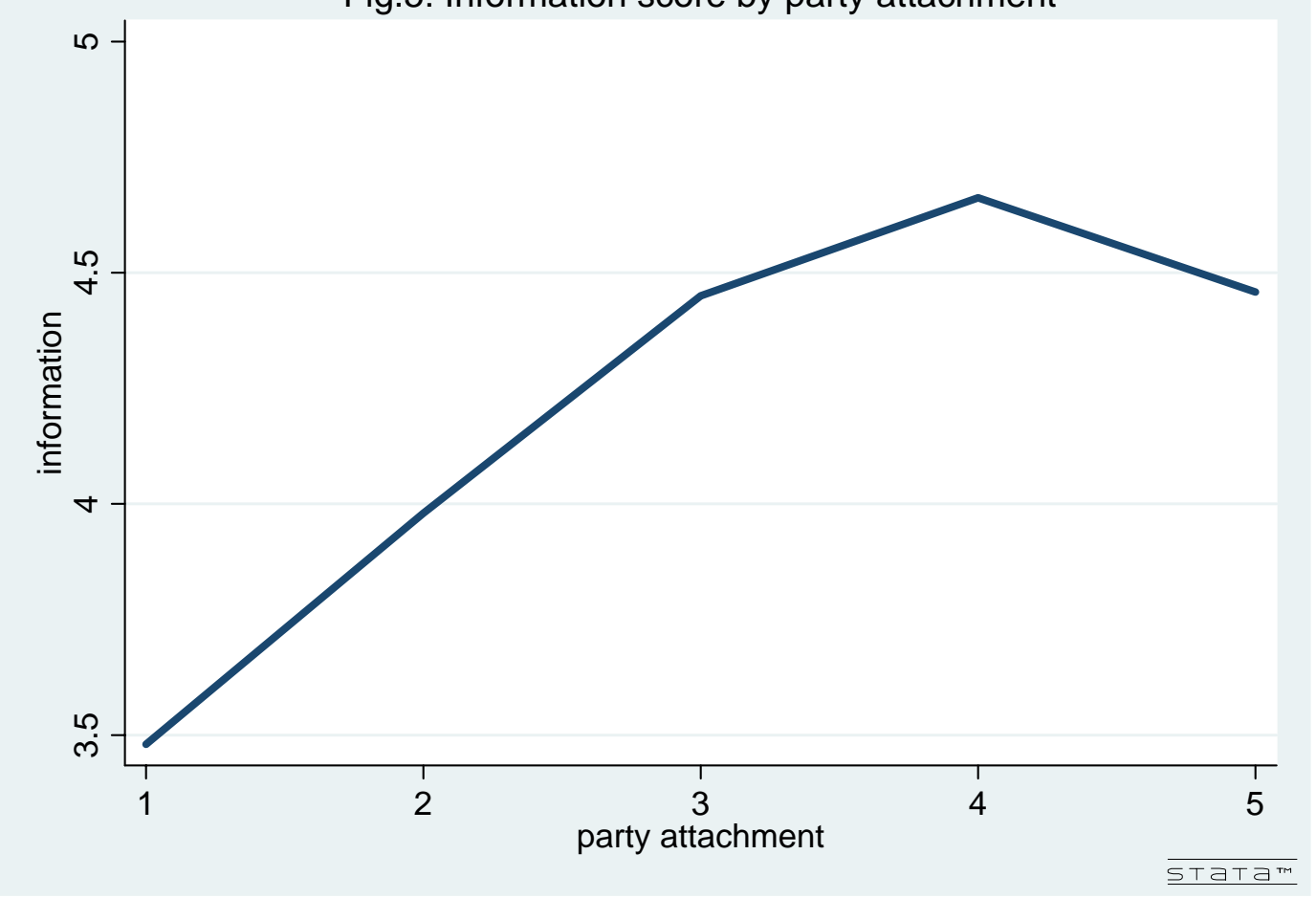


Fig. 1. Summary Statistics

\begin{tabular}{lccccc}
\hline \hline Variable & $\mathrm{N}$ & Mean & Std. Dev. & Min & Max \\
\hline Turnout & 3199 & 0.7983745 & 0.4012767 & 0 & 1 \\
Information & 3199 & 4.267033 & 1.831907 & 0 & 10.62 \\
ideological strenght & 2770 & 2.367148 & 1.554779 & 1 & 6 \\
party attachment & 3199 & 2.751797 & 0.951436 & 1 & 5 \\
hours worked & 3199 & 37.80119 & 15.76359 & 0 & 95 \\
news supply & 3196 & 0.984336 & 2.632574 & 0 & 24.28772 \\
age & 3199 & 49.26602 & 17.8535 & 18 & 95 \\
education & 3199 & 3.515161 & 2.161623 & 1 & 7 \\
married & 3199 & 0.5886214 & 0.4921605 & 0 & 1 \\
sex & 3199 & 0.4573304 & 0.4982539 & 0 & 1 \\
income & 2902 & 7.002757 & 4.589678 & 1 & 16 \\
asian & 3199 & 0.0206314 & 0.1421693 & 0 & 1 \\
black & 3199 & 0.0078149 & 0.0880698 & 0 & 1 \\
church attendance & 3199 & 2.045639 & 2.631966 & 0 & 7 \\
union member & 3199 & 0.5804939 & 0.4935553 & 0 & 1 \\
length of residence & 3199 & 20.38387 & 18.29934 & 0 & 94 \\
farmer & 3199 & 0.0084401 & 0.091496 & 0 & 1 \\
house owner & 3199 & 0.6836511 & 0.4651235 & 0 & 1 \\
canvasser & 3199 & 0.2391372 & 0.4266234 & 0 & 1 \\
phone canvasser & 3199 & 0.0750234 & 0.2634704 & 0 & 1 \\
voted in 1992 & 3199 & 0.8055642 & 0.3958276 & 0 & 1 \\
quality paper reader & 3199 & 0.1137856 & 0.3176003 & 0 & 1 \\
marginality & 3196 & 0.3024487 & 0.1939868 & 0.0051282 & 0.8140044 \\
\% degree in district & 6.011545 & 2.67873 & 1.494145 & 17.97613 \\
\% unempl. in district & 9.28633 & 3.949836 & 2.867953 & 22.48957 \\
\hline \hline Note: summary statsics & & 0.969 & 0 & \\
\hline
\end{tabular}

Note: summary statistics for economic activity and standard region of the respondents are not reported 
Table 2: Voter Information (OLS Coefficients)

\begin{tabular}{|c|c|c|c|c|}
\hline & $(1)$ & $(2)$ & (3) & $(4)$ \\
\hline Dep. Variable & Information & Information & Information & Information \\
\hline Ideological strenght 2 & $\begin{array}{c}0.467^{\star \star \star} \\
(5.00)\end{array}$ & & $\begin{array}{c}0.434^{\star \star \star} \\
(4.48)\end{array}$ & \\
\hline Ideological strenght 3 & $\begin{array}{c}0.555^{\star * \star} \\
(6.05)\end{array}$ & & $\begin{array}{c}0.520^{\star \star \star} \\
(5.34)\end{array}$ & \\
\hline Ideological strenght 4 & $\begin{array}{c}0.434^{\star \star \star} \\
(3.97)\end{array}$ & & $\begin{array}{c}0.407^{\star \star *} \\
(3.56)\end{array}$ & \\
\hline Ideological strenght 5 & $\begin{array}{l}0.281 \\
(1.44)\end{array}$ & & $\begin{array}{l}0.288 \\
(1.48)\end{array}$ & \\
\hline Ideological strenght 6 & $\begin{array}{l}0.092 \\
(0.64)\end{array}$ & & $\begin{array}{l}0.171 \\
(1.12)\end{array}$ & \\
\hline Party attachment 2 & & $\begin{array}{l}0.090 \\
(0.67)\end{array}$ & & $\begin{array}{l}0.077 \\
(0.53)\end{array}$ \\
\hline Party attachment 3 & & $\begin{array}{c}0.367^{\star \star \star} \\
(2.70)\end{array}$ & & $\begin{array}{c}0.245^{\star} \\
(1.65)\end{array}$ \\
\hline Party attachment 4 & & $\begin{array}{c}0.567^{\star * \star} \\
(3.42)\end{array}$ & & $\begin{array}{c}0.491^{* * \star} \\
(2.77)\end{array}$ \\
\hline Party attachment 5 & & $\begin{array}{c}0.402^{\star \star} \\
(2.14)\end{array}$ & & $\begin{array}{c}0.360^{\star} \\
(1.77)\end{array}$ \\
\hline Hours worked (weekly) & $\begin{array}{c}-0.003 \\
(1.08)\end{array}$ & $\begin{array}{c}-0.002 \\
(0.95)\end{array}$ & $\begin{array}{c}-0.005^{\star} \\
(1.76)\end{array}$ & $\begin{array}{c}-0.006^{\star *} \\
(2.09)\end{array}$ \\
\hline News supply & $\begin{array}{c}0.031^{\star * *} \\
(2.66)\end{array}$ & $\begin{array}{c}0.022^{*} \\
(1.71)\end{array}$ & $\begin{array}{c}0.031^{* \star *} \\
(2.59)\end{array}$ & $\begin{array}{l}0.022 \\
(1.64)\end{array}$ \\
\hline age & $\begin{array}{c}0.084^{\star * *} \\
(5.98)\end{array}$ & $\begin{array}{c}0.105^{\star \star \star} \\
(8.22)\end{array}$ & $\begin{array}{c}0.090 * * \star \\
(6.11)\end{array}$ & $\begin{array}{c}0.116^{\star \star \star} \\
(8.52)\end{array}$ \\
\hline age squared & $\begin{array}{c}-0.065^{\star \star \star} \\
(4.51)\end{array}$ & $\begin{array}{c}-0.087^{\star \star \star *} \\
(6.75)\end{array}$ & $\begin{array}{c}-0.070^{\star \star \star} \\
(4.67)\end{array}$ & $\begin{array}{c}-0.096^{\star \star *} \\
(7.05)\end{array}$ \\
\hline education (foreign or other) & $\begin{array}{c}1.310^{\star} \\
(1.77)\end{array}$ & $\begin{array}{c}1.194^{\star \star} \\
(2.23)\end{array}$ & $\begin{array}{c}1.615^{\star \star} \\
(2.08)\end{array}$ & $\begin{array}{c}1.507^{\star \star} \\
(2.37)\end{array}$ \\
\hline education (CSE or equiv.) & $\begin{array}{l}0.221^{\star} \\
(1.92)\end{array}$ & $\begin{array}{c}0.325^{\star \star \star} \\
(3.10)\end{array}$ & $\begin{array}{l}0.159 \\
(1.32)\end{array}$ & $\begin{array}{c}0.263^{\star \star} \\
(2.37)\end{array}$ \\
\hline education (O level or eq.) & $\begin{array}{c}0.462^{\star \star \star} \\
(4.70)\end{array}$ & $\begin{array}{c}0.556^{\star \star \star} \\
(5.94)\end{array}$ & $\begin{array}{c}0.469 * * \star \\
(4.39)\end{array}$ & $\begin{array}{c}0.557^{\star \star \star} \\
(5.48)\end{array}$ \\
\hline education (A level or eq.) & $\begin{array}{c}0.820 * * \star \\
(6.38)\end{array}$ & $\begin{array}{c}0.906^{\star \star \star} \\
(7.77)\end{array}$ & $\begin{array}{c}0.738^{\star \star \star} \\
(5.36)\end{array}$ & $\begin{array}{c}0.858^{\star \star \star} \\
(6.74)\end{array}$ \\
\hline higher educ. below degree & $\begin{array}{c}0.836^{\star \star \star} \\
(7.69)\end{array}$ & $\begin{array}{c}0.920 \star \star \star \\
(8.53)\end{array}$ & $\begin{array}{c}0.764^{\star \star \star} \\
(6.52)\end{array}$ & $\begin{array}{c}0.858^{\star \star \star} \\
(7.33)\end{array}$ \\
\hline education (degree) & $\begin{array}{c}1.291^{\star \star \star} \\
(10.32)\end{array}$ & $\begin{array}{c}1.431^{\star \star \star} \\
(11.98)\end{array}$ & $\begin{array}{c}1.186^{\star \star \star} \\
(8.69)\end{array}$ & $\begin{array}{c}1.407^{\star \star \star} \\
(10.63)\end{array}$ \\
\hline Income & no & no & yes & yes \\
\hline $\begin{array}{l}\text { Observations } \\
\text { R-squared }\end{array}$ & $\begin{array}{l}2769 \\
0.31\end{array}$ & $\begin{array}{l}3196 \\
0.31\end{array}$ & $\begin{array}{l}2459 \\
0.32\end{array}$ & $\begin{array}{c}2798 \\
0.33\end{array}$ \\
\hline
\end{tabular}

All regressions include a constant and the following control variables: married, sex, church attendance (categorical variable), income(categorical variable), farmer, asian, black, lenght of residence in the constituency, houseowner, contacted by a canvasser during the electoral campaign, contacted by phone, voted in the previous election, regular reader of a quality newspaper, type of economic activity (categorical variable), union member, UK standard region (categorical variable), marginality, district unemployment rate, district population percentage with a university degree.

Robust t statistics in parentheses. * significant at 10\%; ** significant at 5\%; *** significant at $1 \%$ 
Table 3: Voter Turnout (Probit Marginal Effects)

\begin{tabular}{|c|c|c|c|c|}
\hline & $\overline{(1)}$ & (2) & (3) & (4) \\
\hline Dep. Variable & Turnout & Turnout & Turnout & Turnout \\
\hline Information & $\begin{array}{c}0.045^{\star \star *} \\
(4.77)\end{array}$ & $\begin{array}{c}0.064^{\star \star \star} \\
(4.34)\end{array}$ & $\begin{array}{c}0.042^{\star \star \star} \\
(4.24)\end{array}$ & $\begin{array}{c}0.058^{\star * *} \\
(3.88)\end{array}$ \\
\hline Ideological strength & $\begin{array}{c}0.039 * * \\
(2.38)\end{array}$ & & $\begin{array}{c}0.038^{\star \star} \\
(2.15)\end{array}$ & \\
\hline Information x Ideology & $\begin{array}{c}-0.006 \\
(1.47)\end{array}$ & & $\begin{array}{c}-0.005 \\
(1.18)\end{array}$ & \\
\hline Party attachment & & $\begin{array}{c}0.115^{\star \star \star} \\
(4.85)\end{array}$ & & $\begin{array}{c}0.109 * \star \star \\
(4.40)\end{array}$ \\
\hline Information $\times$ Party & & $\begin{array}{c}-0.012^{\star \star} \\
(2.13)\end{array}$ & & $\begin{array}{c}-0.011^{*} \\
(1.92)\end{array}$ \\
\hline Hours worked (weekly) & $\begin{array}{c}-0.001^{\star *} \\
(2.20)\end{array}$ & $\begin{array}{c}-0.001^{* *} \\
(1.98)\end{array}$ & 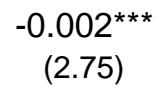 & $\begin{array}{c}-0.002^{\star \star \star} \\
(2.62)\end{array}$ \\
\hline News supply & $\begin{array}{c}-0.002 \\
(0.79)\end{array}$ & $\begin{array}{c}-0.001 \\
(0.36)\end{array}$ & $\begin{array}{c}-0.003 \\
(0.87)\end{array}$ & $\begin{array}{c}-0.001 \\
(0.17)\end{array}$ \\
\hline age & $\begin{array}{c}-0.000 \\
(0.04)\end{array}$ & $\begin{array}{c}-0.002 \\
(0.70)\end{array}$ & $\begin{array}{l}0.002 \\
(0.49)\end{array}$ & $\begin{array}{c}-0.002 \\
(0.53)\end{array}$ \\
\hline age squared & $\begin{array}{c}-0.001 \\
(0.28)\end{array}$ & $\begin{array}{l}0.001 \\
(0.37)\end{array}$ & $\begin{array}{c}-0.002 \\
(0.63)\end{array}$ & $\begin{array}{l}0.001 \\
(0.39)\end{array}$ \\
\hline education (foreign or other) & $\begin{array}{l}0.107 \\
(1.54)\end{array}$ & $\begin{array}{c}0.140^{\star \star} \\
(2.41)\end{array}$ & $\begin{array}{l}0.075 \\
(0.85)\end{array}$ & $\begin{array}{c}0.122^{*} \\
(1.65)\end{array}$ \\
\hline education (CSE or equiv.) & $\begin{array}{l}0.022 \\
(0.84)\end{array}$ & $\begin{array}{l}0.030 \\
(1.17)\end{array}$ & $\begin{array}{l}0.032 \\
(1.13)\end{array}$ & $\begin{array}{l}0.038 \\
(1.37)\end{array}$ \\
\hline education (O level or eq.) & $\begin{array}{l}0.031 \\
(1.28)\end{array}$ & $\begin{array}{c}0.041^{*} \\
(1.75)\end{array}$ & $\begin{array}{l}0.027 \\
(1.02)\end{array}$ & $\begin{array}{l}0.035 \\
(1.36)\end{array}$ \\
\hline education ( $\mathrm{A}$ level or eq.) & $\begin{array}{l}0.013 \\
(0.44)\end{array}$ & $\begin{array}{l}0.025 \\
(0.88)\end{array}$ & $\begin{array}{l}0.009 \\
(0.27)\end{array}$ & $\begin{array}{l}0.015 \\
(0.49)\end{array}$ \\
\hline higher educ. below degree & $\begin{array}{l}0.029 \\
(1.03)\end{array}$ & $\begin{array}{l}0.031 \\
(1.14)\end{array}$ & $\begin{array}{l}0.034 \\
(1.17)\end{array}$ & $\begin{array}{l}0.033 \\
(1.13)\end{array}$ \\
\hline education (degree) & $\begin{array}{c}-0.000 \\
(0.01)\end{array}$ & $\begin{array}{l}0.009 \\
(0.26)\end{array}$ & $\begin{array}{l}0.007 \\
(0.17)\end{array}$ & $\begin{array}{l}0.013 \\
(0.34)\end{array}$ \\
\hline Income & no & no & yes & yes \\
\hline $\begin{array}{l}\text { Pseudo-Rsquared } \\
\text { Observations }\end{array}$ & 2769 & 3196 & 2459 & 2798 \\
\hline
\end{tabular}

All regressions include a constant and the following control variables: married, sex, church attendance (categorical variable), income(categorical variable), farmer, asian, black, lenght of residence in the constituency, houseowner, contacted by a canvasser during the electoral campaign, contacted by phone, voted in the previous election, regular reader of a quality newspaper, type of economic activity (categorical variable), union member, UK standard region (categorical variable), marginality, district unemployment rate, district population percentage with a university degree.

Robust $t$ statistics in parentheses. * significant at 10\%; ** significant at 5\%; *** significant at $1 \%$ 
Table 4: Voter Information in Conservative-Labour races (OLS Coefficients)

\begin{tabular}{|c|c|c|c|c|}
\hline & $(1)$ & $(2)$ & $(3)$ & $(4)$ \\
\hline Dep. Variable & Information & Information & Information & Information \\
\hline Ideological strenght 2 & $\begin{array}{c}0.448^{\star \star \star} \\
(3.57)\end{array}$ & & $\begin{array}{c}0.372^{\star \star \star} \\
(2.87)\end{array}$ & \\
\hline Ideological strenght 3 & $\begin{array}{c}0.563^{\star \star \star} \\
(4.86)\end{array}$ & & $\begin{array}{c}0.484^{\star \star \star} \\
(3.89)\end{array}$ & \\
\hline Ideological strenght 4 & $\begin{array}{c}0.363^{\star \star} \\
(2.45)\end{array}$ & & $\begin{array}{c}0.322^{\star \star} \\
(2.08)\end{array}$ & \\
\hline Ideological strenght 5 & $\begin{array}{l}0.365 \\
(1.39)\end{array}$ & & $\begin{array}{l}0.387 \\
(1.50)\end{array}$ & \\
\hline Ideological strenght 6 & $\begin{array}{l}0.054 \\
(0.27)\end{array}$ & & $\begin{array}{l}0.077 \\
(0.37)\end{array}$ & \\
\hline Party attachment 2 & & $\begin{array}{l}0.269 * \\
(1.69)\end{array}$ & & $\begin{array}{l}0.303^{*} \\
(1.71)\end{array}$ \\
\hline Party attachment 3 & & $\begin{array}{c}0.569 * \star \star \\
(3.50)\end{array}$ & & $\begin{array}{c}0.475^{\star \star \star} \\
(2.60)\end{array}$ \\
\hline Party attachment 4 & & $\begin{array}{c}0.764^{\star \star \star} \\
(3.73)\end{array}$ & & $\begin{array}{c}0.744^{\star * \star} \\
(3.33)\end{array}$ \\
\hline Party attachment 5 & & $\begin{array}{c}0.684^{\star \star \star} \\
(2.87)\end{array}$ & & $\begin{array}{c}0.652^{\star \star} \\
(2.48)\end{array}$ \\
\hline Hours worked (weekly) & $\begin{array}{c}-0.004 \\
(1.16)\end{array}$ & $\begin{array}{c}-0.002 \\
(0.78)\end{array}$ & $\begin{array}{c}-0.005 \\
(1.28)\end{array}$ & $\begin{array}{c}-0.004 \\
(1.22)\end{array}$ \\
\hline News supply & $\begin{array}{c}0.047^{\star * *} \\
(2.97)\end{array}$ & $\begin{array}{l}0.019 \\
(0.96)\end{array}$ & $\begin{array}{c}0.037^{\star \star} \\
(2.22)\end{array}$ & $\begin{array}{l}0.014 \\
(0.72)\end{array}$ \\
\hline age & $\begin{array}{c}0.090^{\star \star \star} \\
(4.78)\end{array}$ & $\begin{array}{c}0.110^{\star \star \star} \\
(6.59)\end{array}$ & $\begin{array}{c}0.094^{\star * \star} \\
(4.78)\end{array}$ & $\begin{array}{c}0.119 * * * \\
(6.63)\end{array}$ \\
\hline age squared & $\begin{array}{c}-0.068^{\star \star \star} \\
(3.60)\end{array}$ & $\begin{array}{c}-0.091^{\star \star *} \\
(5.44)\end{array}$ & $\begin{array}{c}-0.072^{\star \star \star} \\
(3.69)\end{array}$ & $\begin{array}{c}-0.099 * \star \star \\
(5.52)\end{array}$ \\
\hline education (foreign or other) & $\begin{array}{l}0.640 \\
(0.98)\end{array}$ & $\begin{array}{l}0.646 \\
(1.62)\end{array}$ & $\begin{array}{l}0.898 \\
(1.20)\end{array}$ & $\begin{array}{c}0.876^{\star} \\
(1.70)\end{array}$ \\
\hline education (CSE or equiv.) & $\begin{array}{l}0.105 \\
(0.69)\end{array}$ & $\begin{array}{l}0.180 \\
(1.30)\end{array}$ & $\begin{array}{l}0.014 \\
(0.09)\end{array}$ & $\begin{array}{l}0.097 \\
(0.68)\end{array}$ \\
\hline education (O level or eq.) & $\begin{array}{c}0.459 * * * \\
(3.61)\end{array}$ & $\begin{array}{c}0.529 * \star \star \\
(4.42)\end{array}$ & $\begin{array}{c}0.448^{\star \star \star} \\
(3.26)\end{array}$ & $\begin{array}{c}0.506^{\star \star \star} \\
(3.88)\end{array}$ \\
\hline education (A level or eq.) & $\begin{array}{c}0.935^{\star \star *} \\
(5.40)\end{array}$ & $\begin{array}{c}0.966^{\star \star \star} \\
(6.19)\end{array}$ & $\begin{array}{c}0.853^{\star \star \star} \\
(4.62)\end{array}$ & $\begin{array}{c}0.904^{\star \star *} \\
(5.36)\end{array}$ \\
\hline higher educ. below degree & $\begin{array}{c}0.838^{\star \star \star} \\
(5.69)\end{array}$ & $\begin{array}{c}0.862^{\star \star \star} \\
(5.86)\end{array}$ & $\begin{array}{c}0.783^{\star \star \star} \\
(4.95)\end{array}$ & $\begin{array}{c}0.806 * \star \star \\
(5.02)\end{array}$ \\
\hline education (degree) & $\begin{array}{c}1.375^{\star \star \star} \\
(8.60)\end{array}$ & $\begin{array}{c}1.480 * * \star \\
(9.86)\end{array}$ & $\begin{array}{c}1.273^{\star * \star} \\
(7.16)\end{array}$ & $\begin{array}{c}1.447^{\star \star \star} \\
(8.52)\end{array}$ \\
\hline Income & no & no & yes & yes \\
\hline $\begin{array}{l}\text { Observations } \\
\text { R-squared } \\
\end{array}$ & $\begin{array}{c}1506 \\
0.32 \\
\end{array}$ & $\begin{array}{l}1754 \\
0.33 \\
\end{array}$ & $\begin{array}{c}1345 \\
0.34 \\
\end{array}$ & $\begin{array}{c}1546 \\
0.36 \\
\end{array}$ \\
\hline
\end{tabular}

All regressions include a constant and the following control variables: married, sex, church attendance (categorical variable), income(categorical variable), farmer, asian, black, lenght of residence in the constituency, houseowner, contacted by a canvasser during the electoral campaign, contacted by phone, voted in the previous election, regular reader of a quality newspaper, type of economic activity (categorical variable), union member, UK standard region (categorical variable), marginality, district unemployment rate, district population percentage with a university degree.

Robust t statistics in parentheses. * significant at 10\%; ** significant at 5\%; ${ }^{\star \star \star}$ significant at $1 \%$ 
Table 5: Voter Turnout in Conservative-Labour races (Probit Marginal Effects)

\begin{tabular}{|c|c|c|c|c|}
\hline & (1) & (2) & (3) & (4) \\
\hline Dep. Variable & Turnout & Turnout & Turnout & Turnout \\
\hline Information & $\begin{array}{c}0.053^{\star \star \star} \\
(4.10)\end{array}$ & $\begin{array}{c}0.077^{\star * *} \\
(3.81)\end{array}$ & $\begin{array}{c}0.052^{\star * *} \\
(3.85)\end{array}$ & $\begin{array}{c}0.066^{\star \star \star} \\
(3.19)\end{array}$ \\
\hline Ideological strength & $\begin{array}{c}0.041 * \\
(1.92)\end{array}$ & & $\begin{array}{c}0.044^{*} \\
(1.92)\end{array}$ & \\
\hline Information x Ideology & $\begin{array}{c}-0.007 \\
(1.35)\end{array}$ & & $\begin{array}{c}-0.007 \\
(1.29)\end{array}$ & \\
\hline Party attachment & & $\begin{array}{c}0.136^{\star \star \star} \\
(4.22)\end{array}$ & & $\begin{array}{c}0.128^{\star \star \star} \\
(3.83)\end{array}$ \\
\hline Information x Party & & $\begin{array}{c}-0.016 \text { ** } \\
(2.16)\end{array}$ & & $\begin{array}{c}-0.014^{*} \\
(1.78)\end{array}$ \\
\hline Hours worked (weekly) & $\begin{array}{c}-0.002^{\star *} \\
(2.27)\end{array}$ & $\begin{array}{c}-0.002^{\star *} \\
(2.28)\end{array}$ & $\begin{array}{c}-0.002^{\star \star \star} \\
(2.79)\end{array}$ & $\begin{array}{c}-0.002^{\star \star \star} \\
(2.84)\end{array}$ \\
\hline News supply & $\begin{array}{c}-0.005 \\
(1.10)\end{array}$ & $\begin{array}{c}-0.004 \\
(0.76)\end{array}$ & $\begin{array}{c}-0.005 \\
(1.07)\end{array}$ & $\begin{array}{c}-0.001 \\
(0.25)\end{array}$ \\
\hline age & $\begin{array}{l}0.002 \\
(0.40)\end{array}$ & $\begin{array}{c}-0.001 \\
(0.18)\end{array}$ & $\begin{array}{l}0.006 \\
(1.40)\end{array}$ & $\begin{array}{l}0.001 \\
(0.22)\end{array}$ \\
\hline age squared & $\begin{array}{c}-0.003 \\
(0.80)\end{array}$ & $\begin{array}{l}0.000 \\
(0.01)\end{array}$ & $\begin{array}{c}-0.007 \\
(1.62)\end{array}$ & $\begin{array}{c}-0.001 \\
(0.34)\end{array}$ \\
\hline education (foreign or other) & $\begin{array}{c}0.121^{*} \\
(1.65)\end{array}$ & $\begin{array}{c}0.155^{\star \star} \\
(2.57)\end{array}$ & $\begin{array}{l}0.093 \\
(0.96)\end{array}$ & $\begin{array}{c}0.137^{*} \\
(1.79)\end{array}$ \\
\hline education (CSE or equiv.) & $\begin{array}{c}0.062^{\star} \\
(1.90)\end{array}$ & $\begin{array}{c}0.063^{\star} \\
(1.94)\end{array}$ & $\begin{array}{c}0.067 * \\
(1.91)\end{array}$ & $\begin{array}{c}0.074^{\star \star} \\
(2.19)\end{array}$ \\
\hline education (O level or eq.) & $\begin{array}{l}0.047 \\
(1.46)\end{array}$ & $\begin{array}{c}0.062^{\star \star} \\
(1.97)\end{array}$ & $\begin{array}{l}0.029 \\
(0.83)\end{array}$ & $\begin{array}{l}0.037 \\
(1.13)\end{array}$ \\
\hline education (A level or eq.) & $\begin{array}{l}0.044 \\
(1.10)\end{array}$ & $\begin{array}{l}0.061 \\
(1.63)\end{array}$ & $\begin{array}{l}0.047 \\
(1.09)\end{array}$ & $\begin{array}{l}0.053 \\
(1.34)\end{array}$ \\
\hline higher educ. below degree & $\begin{array}{l}0.025 \\
(0.67)\end{array}$ & $\begin{array}{l}0.045 \\
(1.21)\end{array}$ & $\begin{array}{l}0.032 \\
(0.82)\end{array}$ & $\begin{array}{l}0.047 \\
(1.21)\end{array}$ \\
\hline education (degree) & $\begin{array}{l}0.057 \\
(1.28)\end{array}$ & $\begin{array}{c}0.074^{*} \\
(1.75)\end{array}$ & $\begin{array}{l}0.060 \\
(1.18)\end{array}$ & $\begin{array}{l}0.070 \\
(1.47)\end{array}$ \\
\hline Income & no & no & yes & yes \\
\hline $\begin{array}{l}\text { Pseudo-Rsquared } \\
\text { Observations }\end{array}$ & 1506 & 1754 & 1336 & 1546 \\
\hline
\end{tabular}

All regressions include a constant and the following control variables: married, sex, church attendance (categorical variable), income(categorical variable), farmer, asian, black, lenght of residence in the constituency, houseowner, contacted by a canvasser during the electoral campaign, contacted by phone, voted in the previous election, regular reader of a quality newspaper, type of economic activity (categorical variable), union member, UK standard region (categorical variable), marginality, district unemployment rate, district population percentage with a university degree.

Robust t statistics in parentheses. * significant at $10 \%$; ** significant at $5 \%$; ${ }^{* * *}$ significant at $1 \%$ 